\title{
Cardiac adenoviral S100A1 gene delivery rescues failing myocardium
}

\author{
Patrick Most,, ${ }^{1,2}$ Sven T. Pleger, ${ }^{1,2}$ Mirko Völkers, ${ }^{2}$ Beatrix Heidt, ${ }^{2}$ Melanie Boerries, ${ }^{3}$ \\ Dieter Weichenhan, ${ }^{2}$ Eva Löffler, ${ }^{2}$ Paul M.L. Janssen, ${ }^{4}$ Andrea D. Eckhart, ${ }^{1}$ Jeffrey Martini, ${ }^{1}$ \\ Matthew L. Williams, ${ }^{1}$ Hugo A. Katus, ${ }^{2}$ Andrew Remppis, ${ }^{2}$ and Walter J. Koch ${ }^{1}$
}

${ }^{1}$ Center for Translational Medicine, Department of Medicine, Thomas Jefferson University, Philadelphia, Pennsylvania, USA. ²Department of Internal Medicine III, Division of Cardiology, University of Heidelberg, Heidelberg, Germany. ${ }^{3}$ Maurice E. Mueller Institute, Biozentrum, University of Basel, Basel, Switzerland. ${ }^{4}$ Department of Physiology and Cell Biology, College of Medicine and Public Health, The Ohio State University, Columbus, Ohio, USA.

\begin{abstract}
Cardiac-restricted overexpression of the $\mathrm{Ca}^{2+}$-binding protein $\mathrm{S} 100 \mathrm{~A} 1$ has been shown to lead to increased myocardial contractile performance in vitro and in vivo. Since decreased cardiac expression of S100A1 is a characteristic of heart failure, we tested the hypothesis that $\mathrm{S100A1}$ gene transfer could restore contractile function of failing myocardium. Adenoviral S100A1 gene delivery normalized S100A1 protein expression in a postinfarction rat heart failure model and reversed contractile dysfunction of failing myocardium in vivo and in vitro. $S 100 \mathrm{~A} 1$ gene transfer to failing cardiomyocytes restored diminished intracellular $\mathrm{Ca}^{2+}$ transients and sarcoplasmic reticulum (SR) $\mathrm{Ca}^{2+}$ load mechanistically due to increased SR $\mathrm{Ca}^{2+}$ uptake and reduced SR Ca ${ }^{2+}$ leak. Moreover, $\mathrm{S100A1}$ gene transfer decreased elevated intracellular $\mathrm{Na}^{+}$concentrations to levels detected in nonfailing cardiomyocytes, reversed reactivated fetal gene expression, and restored energy supply in failing cardiomyocytes. Intracoronary adenovirus-mediated $\mathrm{S} 100 \mathrm{~A} 1$ gene delivery in vivo to the postinfarcted failing rat heart normalized myocardial contractile function and $\mathrm{Ca}^{2+}$ handling, which provided support in a physiological context for results found in myocytes. Thus, the present study demonstrates that restoration of $\mathrm{S100A1}$ protein levels in failing myocardium by gene transfer may be a novel therapeutic strategy for the treatment of heart failure.
\end{abstract}

\section{Introduction}

Heart failure (HF) remains a leading cause of mortality in the developed world (1), and this, in part, reflects a lack of therapies targeted to the underlying molecular defects that lead to chronic ventricular dysfunction. Although other systems contribute, there is substantial evidence that abnormal intracellular $\mathrm{Ca}^{2+}$ handling is a crucial component of the impaired contractile performance of the failing heart (2). This defect has been linked to abnormal levels of $\mathrm{Ca}^{2+}$-sensor and regulatory proteins in failing myocardium (3), and restoring diminished key protein levels may therefore represent a strategy to reverse the defect. In this regard, S100A1, a low-molecular-weight $\left(\mathrm{M}_{\mathrm{r}}, 10,000\right) \mathrm{Ca}^{2+}$-binding protein is especially interesting with respect to cardiovascular disease. S100A1, a member of the multigene S100 family, is the most abundant S100 protein isoform in the heart (4) and has been found to be downregulated in human and animal models of heart failure $(5,6)$. Importantly, S100A1 has been newly recognized as a positive inotropic regulator of heart function based on the observation that cardiac-restricted S100A1 overexpression enhances $\mathrm{Ca}^{2+}$ cycling and cardiac contractile performance in vitro and in vivo (7-10). These effects were mainly due to improved cardiac sarcoplasmic

Nonstandard abbreviations used: Ad, adenovirus; ANF, atrial natriuretic factor; $\left[\mathrm{Ca}^{2+}\right]_{e}$, extracellular $\mathrm{Ca}^{2+}$ concentration; CSQ, calsequestrin; FC, failing cardiomyocyte; FS, fractional shortening; HF, heart failure; LVEDP, LV end-diastolic pressure; LVESP, LV end-systolic pressure; M199, medium 199; $\left[\mathrm{Na}^{+}\right]_{\mathrm{i}}$, intracellular $\mathrm{Na}^{+}$concentration; NCX, sodium-calcium exchanger; NFC, nonfailing cardiomyocyte; $\mathrm{pCa}$, $-\log \left[\mathrm{Ca}^{2+}\right]$; PCr, phosphocreatine; PLB, phospholamban; RyR, ryanodine receptor; SERCA2, SR Ca ${ }^{2+}$-ATPase; sham-OP, sham-operated; $\alpha$-sk-actin, $\alpha$-skeletal actin; SR, sarcoplasmic reticulum; TTC, triphenyltetrazolium chloride.

Conflict of interest: The authors have declared that no conflict of interest exists.

Citation for this article: J. Clin. Invest. 114:1550-1563 (2004).

doi:10.1172/JCI200421454 reticulum (SR) $\mathrm{Ca}^{2+}$ handling, and a recent study also provided evidence that S100A1 can improve SR $\mathrm{Ca}^{2+}$ fluxes and contractile force in skeletal muscle (11).

In contrast to conventional positive inotropic agents, S100A1mediated chronic cardiac inotropic actions in normal myocardium were independent of $\beta$-adrenergic signaling, with no alteration of heart rate or signs of myocardial hypertrophy or fibrosis (8). In support of these results, S100A1-deficient hearts display severe inotropic and lusitropic defects, shown by both impaired contractile reserve and rapid progressive deterioration of contractile function in response to acute and chronic hemodynamic stress, respectively (12). Thus, the loss of S100A1 protein in human heart failure may indeed contribute to the $\mathrm{Ca}^{2+}$ dysregulation and deterioration of contractile strength. Interestingly, S100A1 has most recently been shown to inhibit programmed cell death of ventricular cardiomyocytes (13), a process that can significantly contribute to the development and progression of HF.

To date, most of the data showing positive myocardial functional effects with S100A1 overexpression have been derived from studies either using a transgenic mouse model or involving adenovirusmediated gene delivery to nonfailing cultured ventricular cardiomyocytes or engineered heart tissue rather than in the context of HF. Therefore, it is not known whether restoration of S100A1 protein expression in the failing heart in vivo may improve contractile performance and prove to be therapeutic. In this study, we tested this hypothesis using adenovirus-mediated myocardial S100A1 gene delivery to an experimental rat HF model. Results from our translational approach demonstrate that S100A1 gene transfer can normalize S100A1 protein levels and restore contractile function of failing myocardium in vitro and in vivo primarily through a normalization and restoration of myocyte $\mathrm{Ca}^{2+}$ homeostasis. 
A

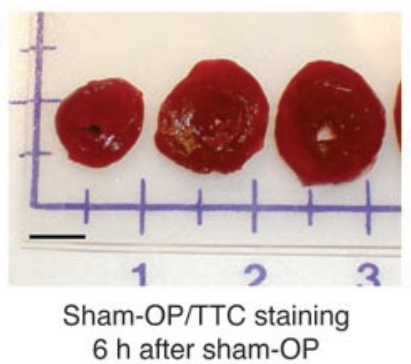

B

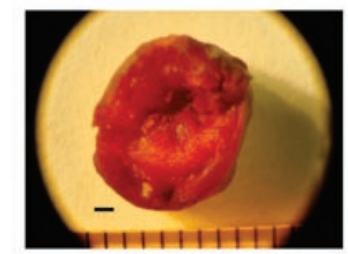

Sham-OP/NFC heart 12 wk after sham-OP

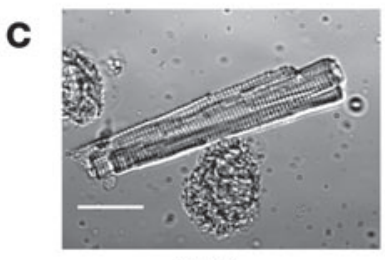

NFC

12 wk after sham-OP

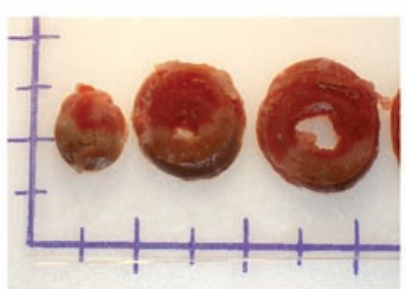

Cryo-MI/TTC staining $6 \mathrm{~h}$ after MI

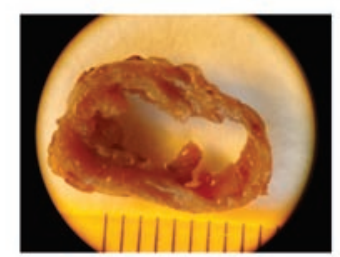

Cryo-MI/FC heart

12 wk after $\mathrm{Ml}$

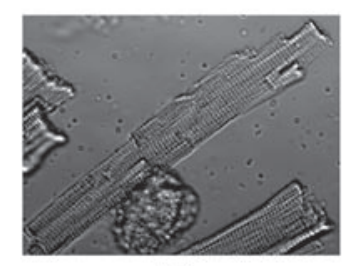

FC

12 wk after MI

\section{Results}

Characterization of experimental heart failure model. Twelve weeks after surgery, cryoinfarcted animals $(n=24)$ (Figure 1A) developed postinfarction HF, as evidenced by marked LV enlargement (Figure $1 B$ ) and depressed in vivo basal and $\beta$-adrenergic-stimulated cardiac function compared with sham-operated (sham-OP) control animals $(n=9)$ (Table 1). Similarly, isolated LV cardiomyocytes from cryoinfarcted hearts displayed evidence of HF with significant depression of contractility and $\mathrm{Ca}^{2+}$ cycling (Table 2 ) as well as a marked increase (31\%) in end-diastolic cell length (Figure 1C) compared with nonfailing cardiomyocytes (NFCs) obtained from sham-OP rats. Quantitative RT-PCR analysis indicated a significant increase in mRNA levels for atrial natriuretic factor (ANF) (42-fold), sodium-calcium exchanger (NCX) (2.7-fold), and $\alpha$-skeletal actin ( $\alpha$-sk-actin) (10-fold) in failing cardiomyocytes (FCs) (Figure 2A). Moreover, FCs exhibited a significant decrease in protein levels for S100A1 (4.1-fold), $\mathrm{SR} \mathrm{Ca}^{2+}$ ATPase (SERCA2) (1.9-fold), and phospholamban (PLB) (1.2-fold) compared with NFCs (Figure 2B). NCX protein in FCs was upregulated (2-fold), while calsequestrin (CSQ) was unchanged compared with NFCs (Figure 2B). These results show that chronic cryoinfarcted rat hearts have the biochemical and functional alterations typical of failing myocardium.

S100A1 gene transfer restores S100A1 protein levels in ventricular FCs in vitro. To assess the impact of cardiac S100A1 gene transfer on ventricular FCs in vitro, we treated adult cardiomyocytes isolated from postinfarcted failing rat hearts with an S100A1 adenovirus

\section{Figure 1}

Postinfarct heart failure model. (A) Representative TTC-stained crosssections of a sham-operated (Sham-OP, left) and a cryoinfarcted (Cryo-MI, right) rat heart 6 hours after surgery. Transmural cryoinfarcted myocardium emerges as brown tissue with a gray-white border zone (right). Scale bar: $5 \mathrm{~mm}$. (B) Representative mid-ventricular cross sections of a sham-operated (left) and cryoinfarcted (right) rat heart 12 weeks after surgery. Scale bar: $1 \mathrm{~mm}$. (C) Representative images of a freshly isolated LV cardiomyocyte from a nonfailing sham-operated (NFC, left) and cryoinfarcted failing heart (FC, right) 12 weeks after surgery. Note the marked increase in end-diastolic length in the FC. Scale bar: $25 \mu \mathrm{m}$.

(AdS100A1). Incubation of FCs with either AdS100A1 (MOI, 5 $\mathrm{PFU} /$ cell) or AdGFP (MOI, $5 \mathrm{PFU} /$ cell) resulted in a nearly $100 \%$ infection rate in both groups, as indicated by the expression of the GFP reporter (Figure 3A). Analysis of S100A1 protein expression 24 hours after gene transfer revealed restoration of S100A1 protein in FCs to levels observed in NFCs (FCs, $0.9 \pm 0.3$; NFCs, $4.2 \pm 0.4$; FCs-AdS100A1, $3.9 \pm 0.5 ; P=$ NS, NFCs vs. FCs-AdS100A1; $P<0.05$, FCs-AdS100A1 vs. FCs; $n=4$ ) (Figure $3 \mathrm{~B})$. Data are given as relative AU normalized to CSQ, which did not change among the different groups, nor did $\alpha$-cardiac actin. In contrast, AdGFP-treated FCs continued to have diminished expression of S100A1 (FCs-AdGFP, $0.8 \pm 0.3$; Figure 3B). The increased S100A1 protein levels detected 24 hours after AdS100A1 treatment did not change aberrant protein expression of SERCA2 (NFCs, $4.2 \pm 0.4$; FCs, $2.1 \pm 0.3$; FCs-AdGFP, $2.2 \pm 0.4$; FCs-AdS100A1, $2.4 \pm 0.2 ; n=4$ ), NCX (NFCs, $0.7 \pm 0.1$; FCs, $1.4 \pm 0.2$; FCs-AdGFP, $1.6 \pm 0.3$; FCs-AdS100A1, $1.5 \pm 0.3$; $n=4$ ) or PLB (NFCs, $1.1 \pm 0.1$; FCs, $0.7 \pm 0.2$; FCs-AdGFP, $0.6 \pm 0.1$; FCs-AdS100A1, $0.6 \pm 0.2 ; n=4)$ compared with either AdGFP-treated or untreated FCs (Figure 3B).

\section{Table 1}

In vivo hemodynamic and biometric parameters of postinfarction rat heart failure model

\begin{tabular}{|c|c|c|c|c|}
\hline & $\begin{array}{l}\text { Sham-OP / Nonfailing } \\
\qquad(n=9)\end{array}$ & $\begin{array}{l}\text { Failing } \\
(n=24)\end{array}$ & $\begin{array}{c}\% \text { Change vs. } \\
\text { sham-OP }\end{array}$ & $P^{A}$ \\
\hline \multicolumn{5}{|l|}{ Hemodynamics } \\
\hline \multicolumn{5}{|l|}{ Basal } \\
\hline $\mathrm{HR}\left(\mathrm{min}^{-1}\right)$ & $272 \pm 09$ & $255 \pm 06$ & $-7 \%$ & 0.2 \\
\hline $\mathrm{LV}+\mathrm{dP} / \mathrm{dt}(\mathrm{mmHg} / \mathrm{s})$ & $6777 \pm 209$ & $5537 \pm 280$ & $-19 \%$ & $<0.01$ \\
\hline LV-dP/dt (mmHg/s) & $5887 \pm 282$ & $4184 \pm 223$ & $-29 \%$ & $<0.01$ \\
\hline LVEDP $(\mathrm{mmHg})$ & $8.51 \pm 0.53$ & $12.53 \pm 0.76$ & $+47 \%$ & $<0.01$ \\
\hline LVESP (mmHg) & $100.6 \pm 2.2$ & $86.7 \pm 2.7$ & $-23 \%$ & $<0.01$ \\
\hline \multicolumn{5}{|l|}{$\begin{array}{l}\text { Isoproterenol } \\
\text { ( } 6 \mu \mathrm{g} / \mathrm{kg} \text { body } \mathrm{wt} / \mathrm{min})\end{array}$} \\
\hline $\mathrm{HR}\left(\min ^{-1}\right)$ & $373 \pm 14$ & $339 \pm 09$ & $-10 \%$ & 0.5 \\
\hline $\mathrm{LV}+\mathrm{dP} / \mathrm{dt}(\mathrm{mmHg} / \mathrm{s})$ & $15162 \pm 740$ & $9537 \pm 639$ & $-38 \%$ & $<0.01$ \\
\hline LV-dP/dt (mmHg/s) & $10427 \pm 570$ & $5537 \pm 280$ & $-47 \%$ & $<0.01$ \\
\hline LVEDP $(\mathrm{mmHg})$ & $12.45 \pm 1.83$ & $16.81 \pm 1.78$ & $+35 \%$ & $<0.01$ \\
\hline LVESP (mmHg) & $155.6 \pm 5.9$ & $115.6 \pm 2.5$ & $-26 \%$ & $<0.01$ \\
\hline \multicolumn{5}{|l|}{ Phenotype } \\
\hline HW $(\mathrm{g})$ & $1.03 \pm 0.07$ & $1.58 \pm 0.7$ & $+53 \%$ & $<0.01$ \\
\hline HW/body wt (mg/g) & $3.03 \pm 0.16$ & $5.48 \pm 0.3$ & $+80 \%$ & $<0.01$ \\
\hline
\end{tabular}

Data were obtained 12 weeks after surgery in anesthetized animals and are presented as mean \pm SEM. HR, heart rate; SEP, systolic ejection pressure; HW, heart weight. ACompared by Student's $t$ test or ANOVA. 
Table 2

Contractile and $\mathrm{Ca}^{2+-h a n d l i n g ~ p r o p e r t i e s ~ o f ~ N F C s ~ a n d ~ v e n t r i c u l a r ~ F C s ~}$

\begin{tabular}{|c|c|c|c|c|}
\hline & NFCs & FCs & $\begin{array}{l}\% \text { Change, } \\
\text { FCs vs. NFCs }\end{array}$ & $P^{A}$ \\
\hline Contractile properties & $(n=30)$ & $(n=33)$ & & \\
\hline \multicolumn{5}{|l|}{ Basal } \\
\hline Fractional shortening (\%) & $10.76 \pm 0.5$ & $5.80 \pm 0.37$ & $-46 \%$ & $<0.01$ \\
\hline$-\mathrm{d} / / \mathrm{d} t(\mu \mathrm{m} / \mathrm{s})$ & $8.27 \pm 0.50$ & $4.09 \pm 0.26$ & $-51 \%$ & $<0.01$ \\
\hline$+\mathrm{d} / / \mathrm{d} t(\mu \mathrm{m} / \mathrm{s})$ & $7.52 \pm 0.50$ & $2.91 \pm 0.34$ & $-61 \%$ & $<0.01$ \\
\hline $\mathrm{EDL}(\mu \mathrm{m})$ & $100.6 \pm 2.9$ & $131.0 \pm 2.7$ & $+31 \%$ & $<0.01$ \\
\hline Diameter ( $\mu \mathrm{m})$ & $24.9 \pm 0.74$ & $27.4 \pm 0.96$ & $+10 \%$ & 0.07 \\
\hline \multicolumn{5}{|l|}{ Isoproterenol (10-6 M) } \\
\hline Fractional shortening (\%) & $19.78 \pm 1.61$ & $7.67 \pm 0.93$ & $-60 \%$ & $<0.01$ \\
\hline$-\mathrm{d} / / \mathrm{d} t(\mu \mathrm{m} / \mathrm{s})$ & $18.20 \pm 1.31$ & $5.52 \pm 0.97$ & $-69 \%$ & $<0.01$ \\
\hline$+\mathrm{d} / / \mathrm{d} t(\mu \mathrm{m} / \mathrm{s})$ & $16.47 \pm 1.92$ & $5.05 \pm 1.20$ & $-61 \%$ & $<0.01$ \\
\hline$\%$ Change in FS\% vs. basal & $+112 \%$ & $+32 \%$ & $-71 \%$ & $<0.01$ \\
\hline $\mathrm{Ca}^{2+}$ handling properties & $(n=100)$ & $(n=94)$ & & \\
\hline \multicolumn{5}{|l|}{ Basal } \\
\hline Ca'2+-transient amplitude (nM) & $326 \pm 15$ & $231 \pm 18$ & $-30 \%$ & $<0.01$ \\
\hline Diastolic $\mathrm{Ca}^{2+}(\mathrm{nM})$ & $208 \pm 10$ & $322 \pm 12$ & $+54 \%$ & $<0.01$ \\
\hline \multicolumn{5}{|l|}{ Isoproterenol (10-6 M) } \\
\hline $\mathrm{Ca}^{2+-t r a n s i e n t ~ a m p l i t u d e ~(n M) ~}$ & $605 \pm 22$ & $346 \pm 33$ & $-42 \%$ & $<0.01$ \\
\hline$\%$ Change in amplitude vs. basal & $+85 \%$ & $+49 \%$ & $-42 \%$ & $<0.01$ \\
\hline
\end{tabular}

Data were obtained from freshly isolated cardiomyocytes 12 weeks after surgery and are presented as mean \pm SEM. Cells were obtained from 4 different preparation in each group. EDL, end diastolic length; ${ }^{A}$ Compared by Student's $t$ test or ANOVA.

increased the $\mathrm{Ca}^{2+}$-transient amplitude in FCs to a degree observed in control NFCs (NFCs, $326 \pm 23 \mathrm{nM}$; FCs, $231 \pm 14 \mathrm{nM}$; FCs-AdGFP, $225 \pm 33 \mathrm{nM}$; FCs-AdS100A1, $300 \pm 25 \mathrm{nM}$ ), whereas infection with AdGFP did not improve decreased $\mathrm{Ca}^{2+}$-transient amplitudes (Figure 4B). In addition, AdS100A1-treated cells showed a significant accelerated decay of $\mathrm{Ca}^{2+}$-transients as assessed by the decay constant $\tau$ (data not shown). Moreover, S100A1 gene transfer also significantly reduced the elevated diastolic $\mathrm{Ca}^{2+}$ overload $\left(\left[\mathrm{Ca}^{2+}\right]_{\mathrm{i}}\right)$ observed in AdGFP-treated and untreated failing cells (NFCs, $208 \pm 13 \mathrm{nM}$; FCs, $322 \pm 25 \mathrm{nM}$; FCs-AdGFP, $310 \pm 34 \mathrm{nM}$; FCsAdS100A1, $247 \pm 16$ nM) (Figure 4C). Application of the SERCA2 inhibitor cyclopyazonic acid $(10 \mu \mathrm{M})$ abrogated the gain in function found in AdS100A1-treated FCs (data not shown).

Figure 4D shows representative original tracings of cytosolic $\left[\mathrm{Ca}^{2+}\right]_{i}$ rise for untreated NFCs and FCs and AdGFP- and AdS100A1-treated FCs in response to rapid application of caffeine $(10 \mathrm{mM})$ and $\mathrm{Ni}^{2+}(5 \mathrm{mM})$ serving as a measure for the SR $\mathrm{Ca}^{2+}$ load. S100A1 gene delivery significantly augmented the amplitude of the caffeine-mediated rise in $\left[\mathrm{Ca}^{2+}\right]_{i}$ to levels observed in control NFCs (NFCs, $787 \pm 33$ nM; FCs, $469 \pm 44$ nM; FCs-AdGFP, $449 \pm 29$ nM; FCs-AdS100A1,

Adenoviral S100A1 gene delivery rescues contractile function of failing ventricular myocytes in vitro. Figure 3C shows representative steadystate twitches from untreated NFCs and FCs (upper panel) and AdGFP- and AdS100A1-treated FCs (lower panel). Recordings were obtained at $2 \mathrm{~Hz}, 37^{\circ} \mathrm{C}$, and $2 \mathrm{mM}$ extracellular $\mathrm{Ca}^{2+}$ concentration $\left(\left[\mathrm{Ca}^{2+}\right]_{\mathrm{e}}\right) 24$ hours after gene transfer. S100A1 gene delivery significantly increased fractional shortening (FS) (NFCs, 10.8\% $\pm 0.49 \%$; FCs, $5.8 \% \pm 0.37 \%$; FCs-AdGFP, $5.1 \% \pm 0.27 \%$; FCs-AdS $100 \mathrm{~A} 1$, $10.5 \% \pm 0.39 \%)$, the rate of cell shortening $(-\mathrm{d} l / \mathrm{d} t)$ (NFCs, $0.82 \pm 0.05$ $\mu \mathrm{m} / \mathrm{ms}$; FCs, $0.41 \pm 0.03 \mu \mathrm{m} / \mathrm{ms}$; FCs-AdGFP, $0.39 \pm 0.03 \mu \mathrm{m} / \mathrm{ms}$; FCs-Ad-S100A1, $0.89 \pm 0.05 \mu \mathrm{m} / \mathrm{ms})$ and relengthening $(+\mathrm{d} l / \mathrm{d} t)$ (NFCs, $0.75 \pm 0.05 \mu \mathrm{m} / \mathrm{m}$; FCs, $0.29 \pm 0.03 \mu \mathrm{m} / \mathrm{m}$; FCs-AdGFP, $0.27 \pm 0.02 \mu \mathrm{m} / \mathrm{m} ;$ FCs-AdS100A1, $0.67 \pm 0.04 \mu \mathrm{m} / \mathrm{m}$ ) in FCs to levels observed in NFCs (Figure 3D). AdGFP treatment did not improve contractility of failing cells (Figure 3D).

S100A1 gene delivery normalizes $\mathrm{Ca}^{2+}$ handling in ventricular FCs in vitro. Figure 4A shows representative steady-state $\mathrm{Ca}^{2+}$ transients obtained under basal conditions from NFCs and FCs 24 hours after AdGFP or AdS100A1 treatment. S100A1 gene transfer significantly

\section{Figure 2}

Reactivated fetal gene expression and abnormal abundance of $\mathrm{Ca}^{2+}$ regulatory proteins in failing myocardium. (A) Reactivated fetal gene expression ( $A N F, N C X$, and $\alpha$-sk-actin) in rat FCs versus NFCs from sham-OP hearts $\left(n=6\right.$; ${ }^{*} P<0.01$, FCs vs. NFCs). Results were obtained from 5 different hearts in each group 12 weeks after surgery. (B) Abnormal protein expression in failing cryoinfarcted rat hearts. Left: Representative results of Western blots for NCX, SERCA2, CSQ, S100A1, and PLB from pooled fractions of FCs $(n=5)$ and NFCs $(n=5)$ from cryoinfarcted and sham-OP rat hearts. Results were obtained 12 weeks after surgery. Right: Average fold change in protein expression in failing cryoinfarcted hearts relative to the sham-OP group $\left(n=7\right.$; ${ }^{*} P<0.01$, FCs vs. NFCs). Data are given as mean \pm SEM.
$709 \pm 19 \mathrm{nM})$ (Figure 4E), which indicates restoration of SR Ca ${ }^{2+}$ content in failing cells by S100A1. In contrast, infection of FCs with AdGFP did not improve diminished SR $\mathrm{Ca}^{2+}$ load (Figure 4E).

S100A1 interacts with SERCA2 and enhances SERCA2 activity in vitro. Subcellular location of adenovirally expressed S100A1 in FCs was
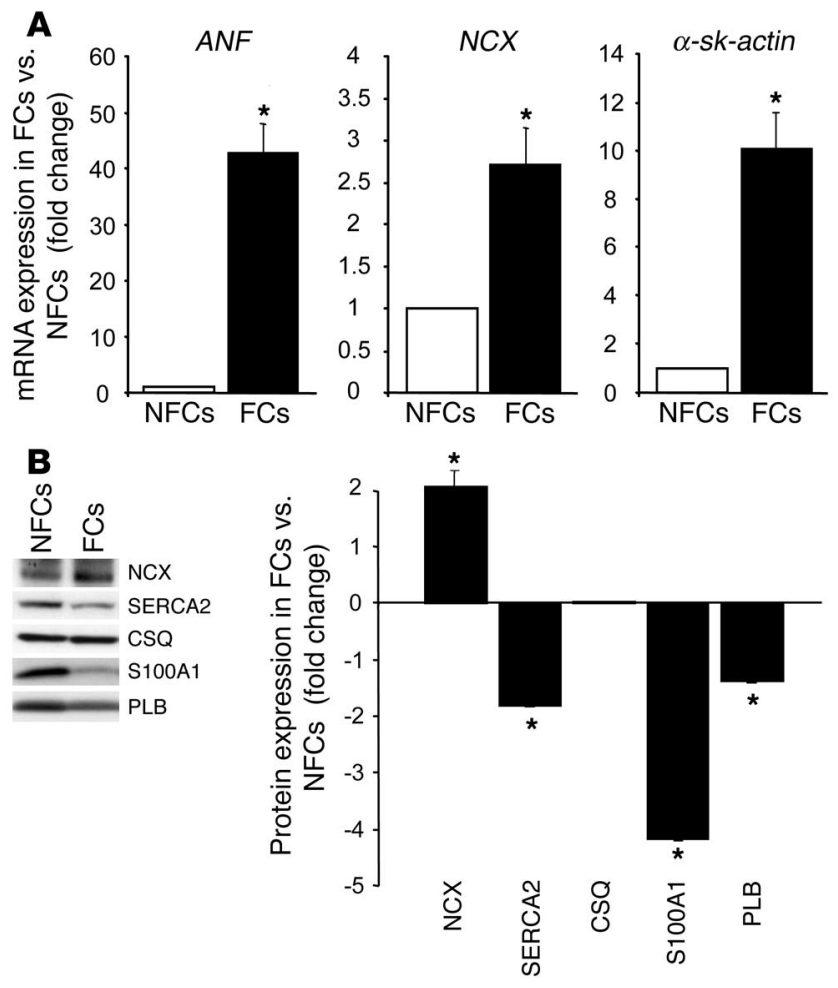
A Transmission
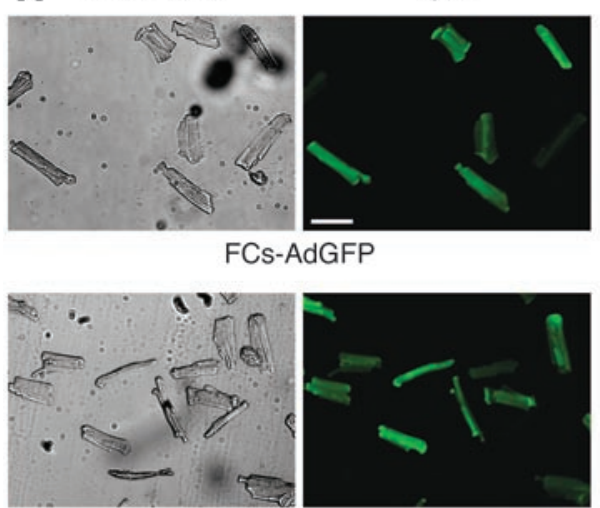

FCs-AdS100A1
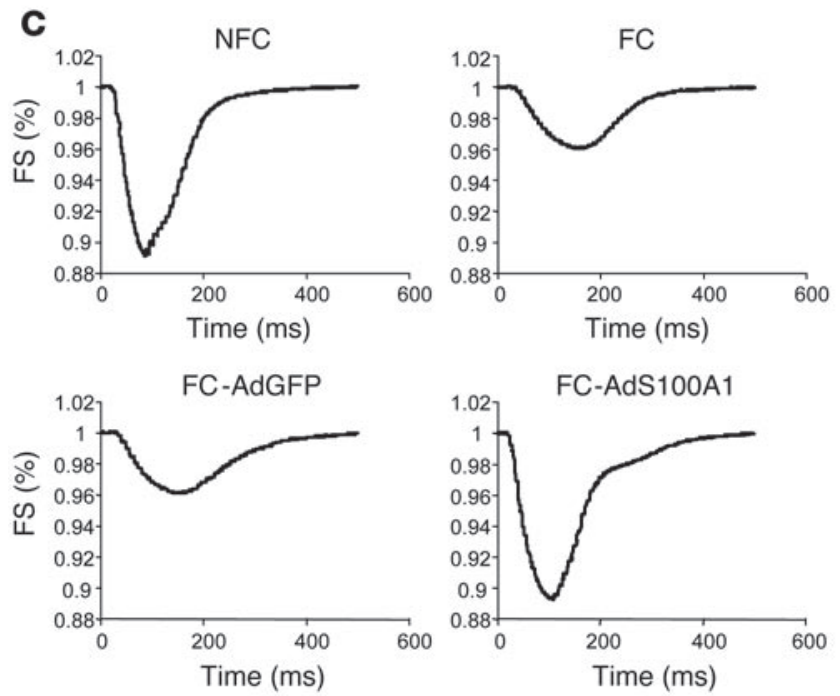

$\mathbf{B}$
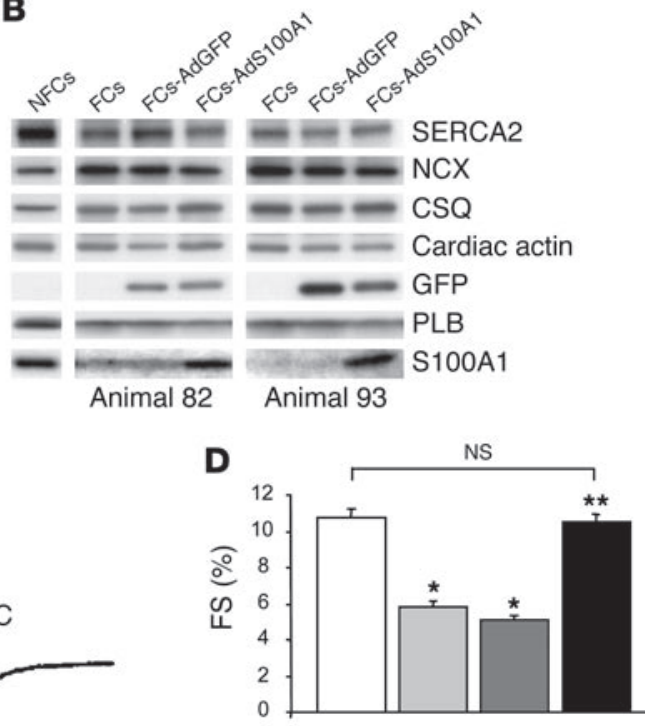

NS
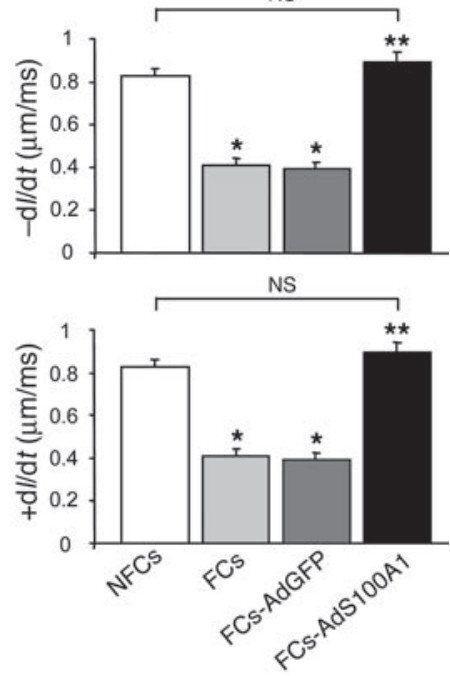

Figure 3

S100A1-mediated rescue of contractile dysfunction in vitro. (A) Efficiency of adenovirus-mediated gene transfer in FCs. Representative transmission (left) and GFP emission images (right) from FCs 24 hours after adenoviral infection. Upper left: FCs-AdGFP transmission; upper right: FCs-AdGFP, 510-nm emission; lower left: FCs-AdS100A1 transmission; lower right: FCs-AdS100A1, 510-nm emission. Scale bar: $100 \mu \mathrm{m}$. (B) Restoration of S100A1 protein levels in FCs 24 hours after S100A1 gene transfer. Representative results of Western blots for SERCA2, NCX, CSQ, cardiac actin, GFP, PLB, and S100A1 from homogenates both of untreated NFCs and FCs and AdGFP- and AdS100A1-transfected FCs. Note that GFP is only expressed in adenovirus-treated failing cells. Data are shown from 2 different representative preparations (animals 82 and 93). (C) Rescue of contractile function in FCs after adenoviral S100A1 gene transfer. Original tracings of FS (shown as downward deflection) from a representative NFC, FC, FC-AdGFP, and FC-AdS100A1. (D) Normalization of FS (upper panel), rate of cellular shortening $(-\mathrm{d} / / \mathrm{d} t ; \mu \mathrm{m} / \mathrm{ms}$; middle panel), and rate of cellular relengthening $(+\mathrm{d} / / \mathrm{d} t ; \mu \mathrm{m} / \mathrm{ms}$; lower panel) in FCs after $\mathrm{S} 100 \mathrm{~A} 1$ gene addition $(n=40$ cells from 4 different preparations in each group; ${ }^{*} P<0.01$ compared with NFCs; ${ }^{* *} P<0.01$ compared with FCs and FCs-AdGFP); $P=\mathrm{NS}$, NFCs vs. FCs-AdS100A1. Data are presented as mean $\pm \mathrm{SEM}$.

investigated by confocal laser scanning microscopy. Anti-S100A1 immunolabeling of AdS100A1-treated FCs revealed a fine granular network-like distribution for S100A1 (blue) throughout the cell that was periodically enhanced nearly every $2 \mu \mathrm{m}$ (Figure 5B, see 3 -fold magnified inset). A similar pattern was obtained for SERCA2 (red) (Figure 5C). Superimposing the 2 images revealed substantial colocalization of S100A1 and SERCA2 (violet) (Figure 5D). This finding was further corroborated by $\mathrm{Ca}^{2+}$-dependent coimmunoprecipitation for S100A1 with SERCA2 in the presence of $1 \mathrm{mM} \mathrm{Ca}^{2+}$ (Figure 5E). Lower levels of free $\mathrm{Ca}^{2+}(1 \mu \mathrm{M})$ also supported this interaction (data not shown). Interestingly, coimmunoprecipitations carried out for SERCA2 and PLB revealed no apparent alteration of the PLB/ SERCA2 interaction by S100A1 (data not shown).

SERCA2 activity was measured in SR preparations derived both from AdS100A1- and AdGFPtreated failing cells as well as NFCs by the use of a pyruvate/ $\mathrm{NADH}$-coupled reaction at $-\log \left[\mathrm{Ca}^{2+}\right]$ (pCa; given in molar) 6.2. SERCA2 activity in AdGFPtreated failing cells was significantly decreased compared with control NFCs (Figure 5F). However, SR preparations from AdS100A1 myocytes had significantly improved $\mathrm{Ca}^{2+}$-dependent SERCA2 activity (NFCs, 0.175 $\pm 0.03 \mu \mathrm{mol} / \mathrm{min} / \mathrm{mg}$ protein; FCs-AdGFP, $0.07 \pm 0.01 \mu \mathrm{mol} /$ $\mathrm{min} / \mathrm{mg}$ protein; FCs-AdS100A1, $0.121 \pm 0.02 \mu \mathrm{mol} / \mathrm{min} / \mathrm{mg}$ protein) (Figure 5F). Further, in accordance with these data, incubation of SR vesicles isolated from FCs-AdGFP myocytes with recombinant human S100A1 protein showed a similar increase in SERCA2 activity (Figure 5G). Testing of distinct regions of S100A1 using oligopeptides revealed that the S100A1-mediated increase in SERCA2 activity is through the carboxyl terminal domain (S100A1-C) of the protein (Figure 5G).

S100A1 interacts with SERCA2 and increases SERCA2 activity in COS cells. Coexpression of S100A1 and SERCA2 in COS cells was carried out to confirm the impact of S100A1 on SR $\mathrm{Ca}^{2+}$ handling seen in myocardial tissue. COS cells were incubated with 100 viral particles per cell to achieve $100 \%$ transfection (data not shown). Figure $6 \mathrm{~A}$ shows representative Western blot images for adenovirally overexpressed SERCA2 and S100A1 protein in COS cell lysates. Staining for $\beta$-actin served as a control for equal protein loading. Assessment of $\mathrm{Ca}^{2+}$-ATPase activity in COS microsomal fractions was carried out in the presence of $600 \mathrm{nM}$ free $\mathrm{Ca}^{2+}$ concentration 
A NFC $\quad$ FC $\quad$ FC-AdGFP FC-AdS100A1
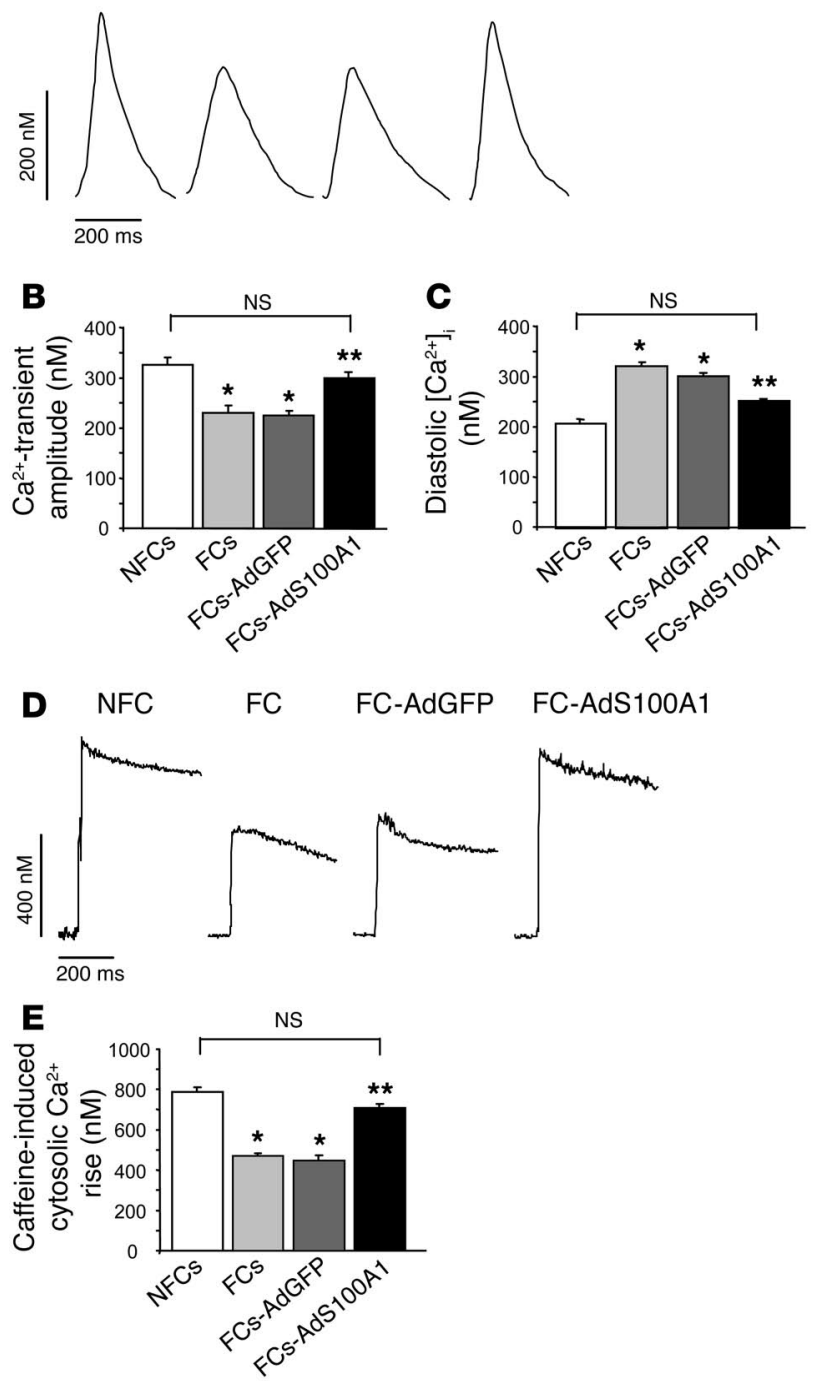

(pCa 6.2). As shown in Figure 6B (left panel), coexpression of S100A1 enhanced $\mathrm{Ca}^{2+}$-ATPase activity of SERCA2 by $44 \%$. Notably, the S100A1-mediated increase in SERCA2 activity could be prevented by addition of an anti-S100A1 antibody (10 $\mu 1$ SA 5632), whereas application of the antibody preincubated with an S100A1 blocking peptide (S100A1 AAs 42-54) did not abrogate the S100A1-mediated effect. Thapsigargin (TG) $\left(10^{-6} \mathrm{M}\right)$ completely abolished the ATPase activity both in SERCA2- and S100A1/ SERCA2-overexpressing COS cells, which confirmed the specificity of the measurements. As with adenovirally coexpressed S100A1 protein, addition of $1 \mu \mathrm{M}$ of human recombinant S100A1 protein also significantly increased the $\mathrm{Ca}^{2+}$-ATPase activity in SERCA2overexpressing COS cells (Figure 6B, right panel).

Coimmunoprecipitations carried out for adenovirally expressed S100A1 and SERCA2 in COS cells confirmed the $\mathrm{Ca}^{2+}$-dependent interaction of both molecules observed in myocardium. As shown in Figure 6C, S100A1 coimmunoprecipates SERCA2 only in the presence of $1 \mu \mathrm{M}$ free $\mathrm{Ca}^{2+}$ concentration but not in the presence of EGTA. S100A1 also coprecipitates with SERCA2 in the presence of $1 \mathrm{mM} \mathrm{Ca}^{2+}$ (data not shown). The specificity of this finding was confirmed by testing the S100A1 antibody preincubated with an

\section{Figure 4}

Normalization of $\mathrm{Ca}^{2+}$ transients and SR $\mathrm{Ca}^{2+}$ load after S100A1 gene delivery in FCs. (A) Original tracings of $\mathrm{Ca}^{2+}$ transients (shown as upward deflection) from a representative NFC, FC, FC-AdGFP, and FC-AdS100A1. (B) Normalization of $\mathrm{Ca}^{2+}$-transient amplitude (nM) and $(\mathbf{C})$ significant decrease in diastolic $\left[\mathrm{Ca}^{2+}\right](\mathrm{nM})$ in failing cells after AdS100A1 treatment $(n=40$ cells from 4 different preparations in each group). (D) Original tracings of cytosolic $\mathrm{Ca}^{2+}$ rise in response to acute caffeine application $(10 \mathrm{mM})$ in the presence of $\mathrm{Ni}^{2+}(5 \mathrm{mM})$ (shown as upward deflection) from a representative NFC, FC, FCAdGFP, and FC-AdS100A1. (E) Normalization of SR Ca2+ load estimated from the caffeine-induced cytosolic $\mathrm{Ca}^{2+}$ rise $(\mathrm{nM})$ in $\mathrm{FCs}$ after AdS100A1 gene transfer ( $n=40$ cells from 4 different preparations in each group). ${ }^{*} P<0.01$ compared with NFCs; ${ }^{*} P<0.01$ compared with FCs and FCs-AdGFP; $P=$ NS, NFCs vs. FCs-AdS100A1. Data are presented as mean \pm SEM.

S100A1 blocking peptide that neither precipitated S100A1 protein nor coprecipitated SERCA2 (Figure 6C).

S100A1 interacts with the ryanodine receptor 2 and reduces the SR Ca ${ }^{2+}$ leak. Since S100A1 has been shown to interact with ryanodine receptor (RyR) in striated muscle (14), we investigated whether adenovirally expressed S100A1 might associate with the SR $\mathrm{Ca}^{2+}$-release channel in FCs. Figure 7 shows representative confocal images for S100A1 (blue) (Figure 7B) and RyR2 (red) (Figure 7C) in myocytes after AdS100A1 treatment. Merging the corresponding pictures revealed partial colocalization for S100A1 with the RyR2 (violet) (Figure 7D, see 3-fold magnified inset). As shown in Figure 7E, $\mathrm{Ca}^{2+}$-dependent $(1 \mathrm{mM})$ coimmunoprecipitation of S100A1 with RyR2 in failing cells provides further evidence for the association of both proteins. This was also evident with lower $\mathrm{Ca}^{2+}(1 \mu \mathrm{M}$; data not shown). Since S100A1 gene transfer resulted in restored $\mathrm{SR} \mathrm{Ca}{ }^{2+}$ content and decreased diastolic $\left[\mathrm{Ca}^{2+}\right]_{i}$, we investigated whether $\mathrm{S} 100 \mathrm{~A} 1 \mathrm{might}$ affect the SR $\mathrm{Ca}^{2+}$ leak in failing myocardium. Figure 7F (upper panel) shows the representative time course of the $\mathrm{Ca}^{2+}$ leak from SR vesicles derived from nonfailing as well as AdGFP- and AdS100A1-treated failing myocardium in the presence $(+)$ of TG (1 $\mu \mathrm{M})$ after $\mathrm{Ca}^{2+}$ uptake induced by MgATP. In contrast to nonfailing $\mathrm{SR}$ vesicles, a prominent $\mathrm{Ca}^{2+}$ leak was observed in nontreated and AdGFP-treated failing myocardium that was significantly reduced after AdS100A1 treatment.

S100A1 modulates activity of the cardiac SR $\mathrm{Ca}^{2+}$-release channel. The influence of S100A1 on RyR2 activity was further investigated in cardiac SR vesicle preparations. RyR2 activity was indirectly measured by assessment of $\mathrm{Ca}^{2+}$-dependent RyR2 [ $\left.{ }^{3} \mathrm{H}\right]$-ryanodine binding in the presence and absence of $1 \mu \mathrm{M}$ human recombinant S100A1. As shown in Figure 8, S100A1 modulates RyR2 $\left[{ }^{3} \mathrm{H}\right]$-ryanodine binding in a biphasic manner. Applied S100A1 apparently reduced $\left[{ }^{3} \mathrm{H}\right]$-ryanodine binding and RyR2 open probability, at least in the presence of $150 \mathrm{nM}$ free $\mathrm{Ca}^{2+}$ concentration. However, in the presence of increasing $\mathrm{Ca}^{2+}$ concentrations, S100A1 enhanced $\left[{ }^{3} \mathrm{H}\right]$-ryanodine binding, which implicates increased activity of the RyR2. Thus, decreased RyR2 activity at diastolic $\mathrm{Ca}^{2+}$ concentrations might account at least in part for the S100A1-caused decrease in the SR $\mathrm{Ca}^{2+}$ leak, whereas enhanced RyR2 activity at supradiastolic $\mathrm{Ca}^{2+}$ concentrations might contribute to the S100A1-mediated increase in $\mathrm{Ca}^{2+}$-transient amplitude in normal cardiomyocytes $(7,8)$ and even FCs.

Fetal gene expression in ventricular FCs in vitro is reversed after AdS100A1 treatment. As assessed by quantitative real-time PCR, normalization of S100A1 protein levels in FCs significantly sup- 

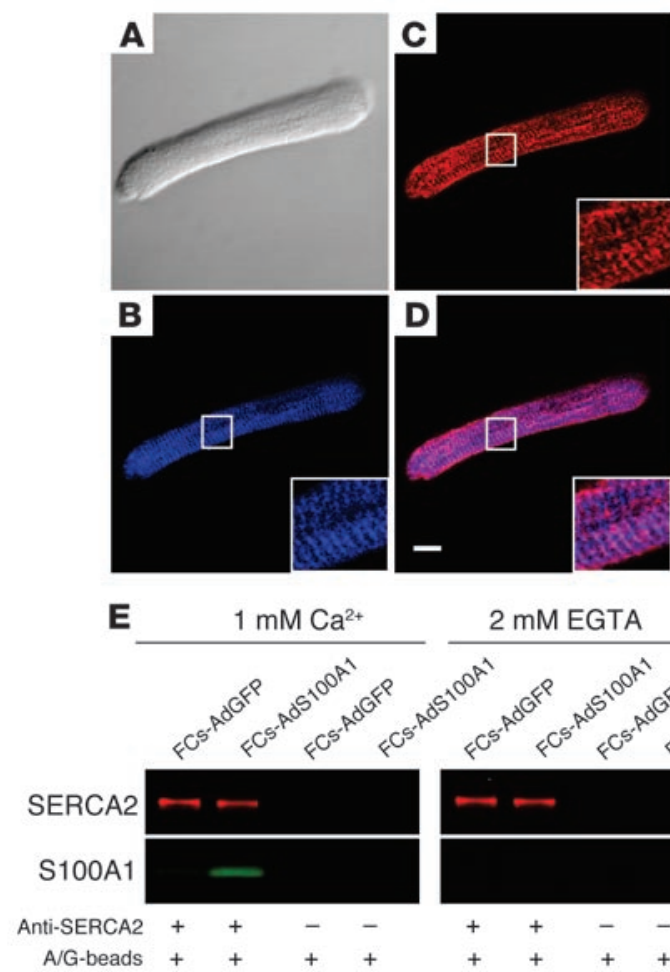

\section{Figure 5}

S100A1 interacts with SERCA2 and increases activity of the SR Ca ${ }^{2+}$ pump in failing myocardium. (A) Nomarski image of an FC-AdS100A1. Immunolabeling of (B) S100A1 (blue) and (C) SERCA2 (red) in the same cell. (D) Overlay of B and C depicts colocalization of SERCA2 and S100A1 (violet). Scale bar: $20 \mu \mathrm{m}$. Inset magnification, $\times 3$. (E) Ca ${ }^{2+}$-dependent coimmunoprecipitation of SERCA2 (red) and S100A1 (green). Samples were immunoprecipated with anti-SERCA2 antibody and costained for S100A1. Control experiments were carried out with A/G-Sepharose beads (A/G-beads) only. (F) Enhancement of $\mathrm{Ca}^{2+-}$ dependent $\mathrm{Ca}^{2+}$-ATPase activity in homogenates of FCs-AdS100A1. (G) Coincubation of FC-AdGFP homogenates with human recombinant S100A1 protein (rhS100A1) and S100A1 peptides enhances SERCA2 activity. Experiments were carried out at pCa $6.2(n=6) .{ }^{*} P<0.01$, NFCs vs. FCs; ${ }^{* *} P<0.01$, FCs-AdS100A1 and FCs-AdGFP + S100A1 protein or peptides vs. FCs-AdGFP. Pooled cardiomyocyte samples were obtained from 4 different preparations in each group. Data are presented as mean \pm SEM.

pressed increased mRNA expression of ANF (Figure 9A) (NFCs, $1 \mathrm{AU}$; FCs, $42 \pm 06$ AU; FCs-AdGFP, $37 \pm 07$ AU; FCs-AdS100A1, $24 \pm 05 \mathrm{AU}$ ) and essentially normalized NCX mRNA (Figure 9B) (NFCs, $1 \mathrm{AU}$; FCs, $2.7 \pm 0.5 \mathrm{AU}$; FCs-AdGFP, $2.9 \pm 0.3 \mathrm{AU}$; FCsAdS100A1, $1.23 \pm 0.2 \mathrm{AU}$ ) within 24 hours, whereas AdGFP infection revealed no alterations of these genes.

AdS100A1 treatment normalizes intracellular $\mathrm{Na}^{+}$concentration in ventricular FCs in vitro. We next addressed the impact of S100A1 gene transfer on disturbed intracellular $\mathrm{Na}^{+}$handling in FCs by the measurement of the $\mathrm{Na}^{+}$-fluorescent indicator sodium-binding benzofuran-isophthalate acetoxymethylester. Steady-state intracellular $\mathrm{Na}^{+}$concentration $\left(\left[\mathrm{Na}^{+}\right]_{i}\right)$ was found to be significantly increased both in untreated and AdGFP-treated FCs compared with control NFCs, both at rest (FCs, $16.12 \pm 0.36 \mathrm{mM}$; FCs-AdGFP, $16.12 \pm 0.36$ $\mathrm{mM} ; \mathrm{N}, 11.21 \pm 0.41 \mathrm{mM})$ and under electrical stimulation (2 $\mathrm{Hz}$ ) (FCs, $20.21 \pm 0.49$ mM; FCs-AdGFP, $20.24 \pm 0.68 \mathrm{mM}$; NFCs, $15.04 \pm 0.39 \mathrm{mM}$ ) (Figure 9C). However, S100A1 gene transfer decreased elevated $\left[\mathrm{Na}^{+}\right]_{\mathrm{i}}$ in FCs under both conditions to levels observed in NFCs (resting FCs-AdS100A1, $10.67 \pm 0.49 \mathrm{mM} ; 2-\mathrm{Hz}$ FCs-AdS100A1, $13.80 \pm 0.47 \mathrm{mM}$ ) (Figure 9C).

Improved contractile reserve in ventricular FCs after AdS100A1 treatment in vitro. AdS100A1 infection significantly improved the blunted $\beta$-adrenergic contractile response of FCs compared with AdGFP-treated and untreated failing cells (Figure 10A). However,
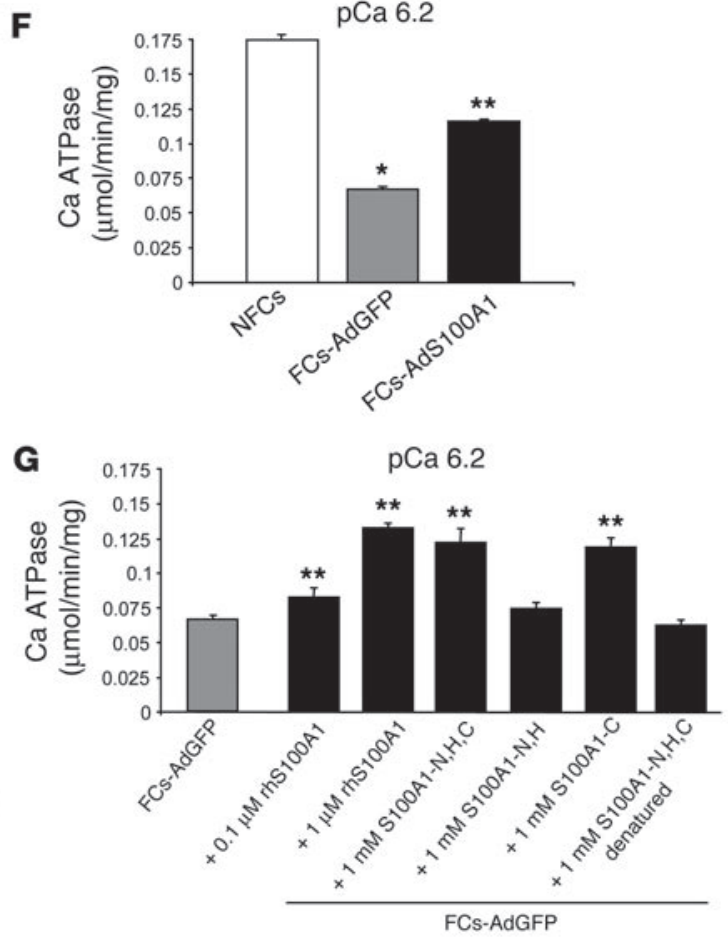

phosphorylation of PLB serine-16, reflecting cAMP-dependent protein kinase activity, was unchanged in AdS100A1-infected FCs compared with controls (Figure 10B). Note that treatment of NFCs with isoproterenol resulted in a visibly higher amount of PLB serine-16 phosphorylation than in FCs.

AdS100A1 gene transfer rescues high energetic phosphate production in ventricular FCs in vitro. Levels of high-energy phosphates in NFCs and FCs were determined by high-performance liquid chromatography. Figure 10C shows that the ratio of total amounts of phosphocreatine (PCr) to ATP was significantly lower in failing than in NFCs, which indicates impaired energy production. Importantly, AdS100A1 treatment recovered the PCr/ATP ratio to values of NFCs (NFCs, $2.43 \pm 0.1 \mathrm{AU}$; FCs, $1.39 \pm 0.1 \mathrm{AU}$, FCsAdGFP; $1.48 \pm 0.2 \mathrm{AU}$; FCs-AdS100A1, $2.4 \pm 0.1 \mathrm{AU})$.

Cardiac AdS100A1 gene transfer restores S100A1 protein levels in failing hearts in vivo. Having shown that S100A1 gene transfer normalized function of ventricular FCs in vitro, we next addressed the question whether in vivo intracoronary adenovirus-mediated S100A1 delivery might restore contractile function of failing rat hearts. We applied a catheter-based adenoviral delivery technique that has previously been shown to achieve global and relatively homogenous transgene expression throughout rat myocardium (15). Figure 11 shows representative confocal Nomarski and GFP fluorescence images of midventricular cryosections of sham-OP 
A

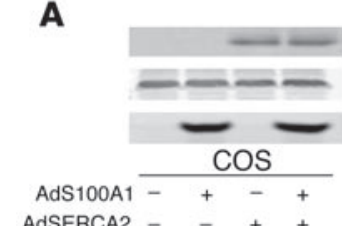

SERCA2

B-Actin

S100A1

AdSERCA2 - - + +

\section{c}

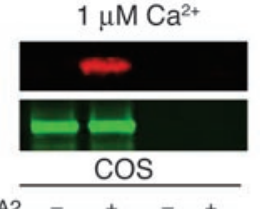
Anti-S100A1 Ab S100A1 hinge peptide + anti-S100A1 Ab A/G-sepharose

\begin{tabular}{|c|c|c|c|}
\hline- & + & - & + \\
\hline+ & + & + & + \\
\hline+ & + & - & - \\
\hline - & - & + & + \\
\hline+ & + & + & + \\
\hline
\end{tabular}

B

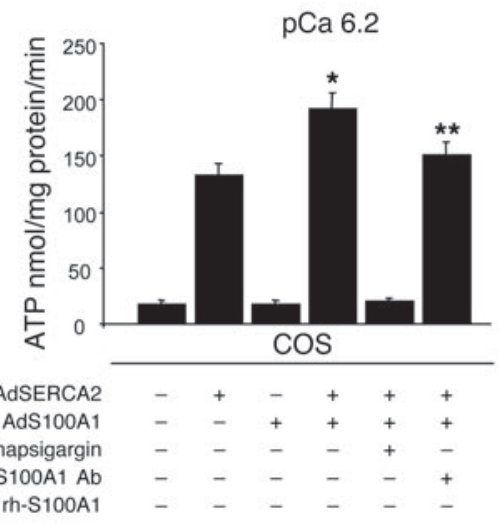

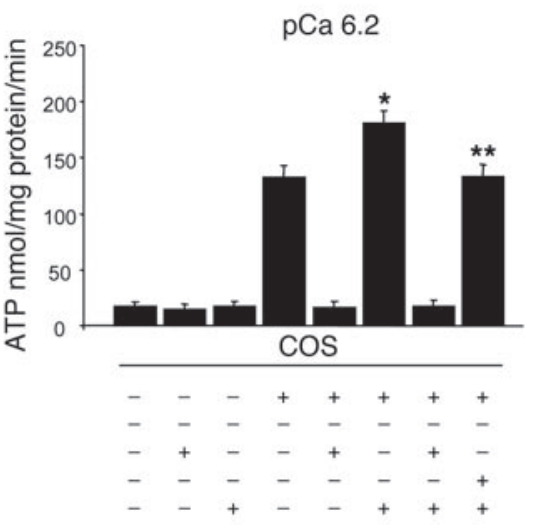

Figure 6

S100A1 interacts with SERCA2 and increases activity of the SR Ca ${ }^{2+}$ pump in COS cells. (A) Representative Western blots given for adenovirally expressed S100A1 and SERCA2 in COS cells. $\beta$-Actin staining served as loading control. (B) Left: Enhanced $\mathrm{Ca}^{2+}$-dependent ATPase activity in SERCA2-expressing COS cells by coexpressed S100A1 protein. Expression of $\mathrm{S} 100 \mathrm{~A} 1$ alone did not alter $\mathrm{Ca}^{2+}$-dependent ATPase activity in COS cells. Note that addition of anti-S100A1 antibody abrogated the S100A1-mediated increase in $\mathrm{Ca}^{2+}$-dependent ATPase activity. Right: Increased $\mathrm{Ca}^{2+}$-dependent ATPase activity in SERCA2-expressing COS cells following application of human recombinant S100A1 protein (rh-S100A1, $1 \mu \mathrm{M})$. Application of anti-S100A1 antibody (10 $\mathrm{ul}$ ) abrogated the S100A1-mediated enhancement of $\mathrm{Ca}^{2+}$-dependent ATPase activity. Application of the SERCA2 inhibitor thapsigargin $\left(10^{-6} \mathrm{M}\right)$ abolished $\mathrm{Ca}^{2+}$-dependent ATPase activity in AdSERCA2-infected COS cells. Experiments were carried out at pCa $6.2(n=3)$. ${ }^{\star} P<0.01$ vs. AdSERCA2; ${ }^{\star \star} P<0.01$ vs. AdS100A1/AdSERCA2. Data are presented as mean \pm SEM. (C) $\mathrm{Ca}^{2+}$-dependent coimmunoprecipitation of SERCA2 (red) and S100A1 (green). Samples were immunoprecipated with anti-S100A1 antibody and costained for SERCA2. Control experiments were carried out with an anti-S100A1 antibody preincubated with a blocking peptide.

(A and B) as well as AdS100A1- (C and D) and AdGFP-treated ( $\mathrm{E}$ and $\mathrm{F})$ postinfarcted rat hearts, respectively. To assess the amount of gene expression in these hearts 7 days after AdS100A1 $(n=7)$ and AdGFP $(n=7)$ intracoronary gene transfer, we analyzed cardiac S100A1 and GFP protein levels by Western blotting. As shown in Figure 11G, infection with AdGFP did not alter downregulated S100A1 protein compared with failing saline-treated hearts $(n=7)$ (FCs-AdGFP, $0.7 \pm 0.2 \mathrm{AU}$; FCs-saline, $0.6 \pm 0.3 \mathrm{AU} ; P=\mathrm{NS}$, FCs-AdGFP vs. FCs-saline; $n=4$ ), whereas delivery with AdS100A1 resulted in normalized cardiac S100A1 protein compared with sham-OP nonfailing hearts $(n=9)$ (FCsAdS100A1, $2.2 \pm 0.3$; sham-OP, $2.5 \pm 0.4 ; P=$ NS, FCs-AdS100A1 vs. sham-OP; $P<0.05$, FCs-AdS100A1 vs. FCs-AdGFP and FCssaline; $n=4)$. The data are given as relative $\mathrm{AU}$ normalized to unchanged CSQ for each group. Note that GFP protein expression was only detected in treated hearts (Figure 11G).

AdS100A1 gene transfer recovers contractile function of failing hearts in vivo. To gain further insight into the physiological consequences mediated in vivo gain in cardiac function was preserved after $\beta$-adrenergic stimulation. As shown in Figure $11 \mathrm{M}$, the isoproterenol-stimulated increase in heart rate was not significantly different between AdS100A1-treated and control failing hearts; however, AdS100A1-treated failing myocardium displayed improved systolic contractile function in response to isoproterenol (Figure 11, N and O). In line with these findings, LV cardiomyocytes isolated from AdS100A1-infected hearts displayed increased contractility (FS: HF-AdGFP, $4.2 \% \pm 0.13 \%$; HFAdS100A1, 8.1\% $\pm 0.51 \% ; P<0.05$, HF-AdS100A1 vs. HF-AdGFP; $n=60$ cells; isolated from 3 different animals in each group) and intracellular $\mathrm{Ca}^{2+}$ transients (HF-AdGFP, $188 \pm 10 \mathrm{nM}$; HFAdS100A1, $309 \pm 37 \mathrm{nM} ; P<0.05$, HF-AdS100A1 vs. HF-AdGFP; $n=60$ cells; isolated from 3 different animals in each group) compared with FCs derived from AdGFP-treated hearts.

Cardiac AdS100A1 gene delivery in vivo reverses fetal gene expression. RTPCR analysis of in vivo AdS100A1-treated failing rat hearts revealed a significant attenuation of elevated mRNA levels for ANF, NCX, and $\alpha$-sk-actin mRNA levels 7 days after gene transfer (Figure 12A). 

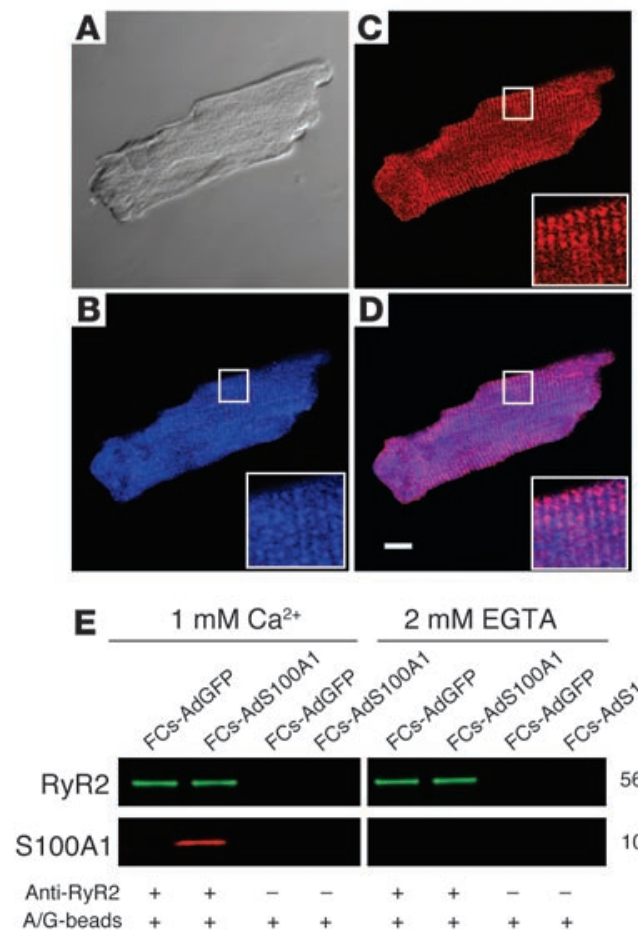

$\mathbf{F}$
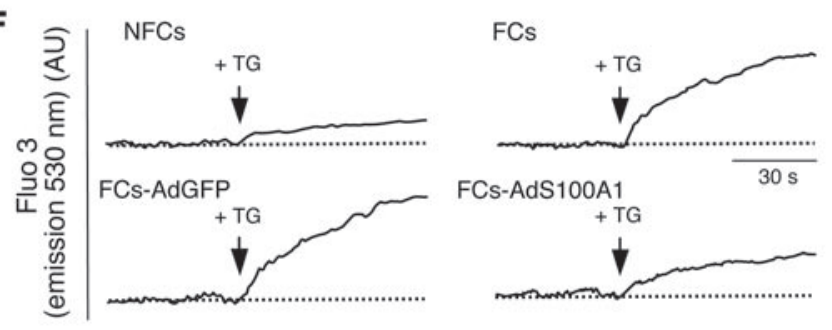

G

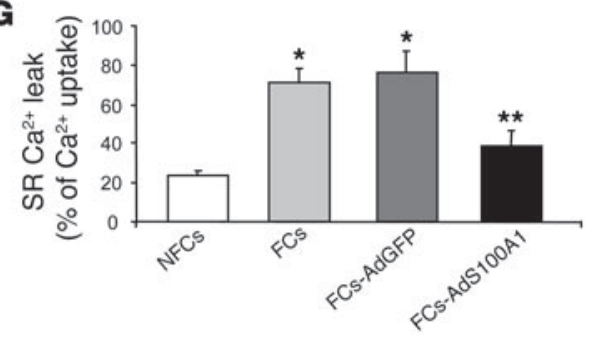

Figure 7

S100A1 interacts with RyR2 and reduces the SR Ca ${ }^{2+}$ leak in failing myocardium. (A) Nomarski image of an NFC-AdS100A1. Immunolabeling of (B) S100A1 (blue) and (C) RyR2 (red) in the same cell. (D) Overlay of B and C depicts colocalization of S100A1 and RyR2 (violet). Scale bar: $20 \mu \mathrm{m}$. Inset magnification, $\times 3$. (E) $\mathrm{Ca}^{2+}$-dependent coimmunoprecipitation of RyR2 (green) and S100A1 (red). Control experiments were carried out with A/G-Sepharose beads only. $(\mathbf{F}$ and $\mathbf{G})$ Typical tracings of the time course $(\mathbf{F})$ and averaged values $(\%)(\mathbf{G})$ of the SR Ca ${ }^{2+}$ leak in nonfailing and failing myocardium and AdGFP- and AdS100A1-transfected failing myocardium. Arrow indicates addition of thapsigargin (+TG; $1 \mu \mathrm{M})(n=4) .{ }^{*} P<0.01$, NF vs. F and F-AdGFP; ${ }^{* *} P<0.01$, F-AdS100A1 vs. F and F-AdGFP; $P=$ NS, NF vs. F-AdS100A1. Data are presented as mean \pm SEM.

Moreover, Western blot analysis of failing rat myocardium after AdS100A1 intracoronary delivery yielded a significant decrease in elevated NCX protein levels (sham-OP, $1.3 \pm 0.4 \mathrm{AU}$; HF-control, $2.4 \pm 0.3 \mathrm{AU}$; FCs-AdS100A1, $1.6 \pm 0.3 \mathrm{AU} ; n=4 ; P<0.05$, HF-S100A1 vs. HF-control) and a significant increase in SERCA2 (sham-OP, $3.5 \pm 0.8$; HF-control, $1.4 \pm 0.6$; FCs-AdS100A1, $2.9 \pm 0.3 ; n=4$; $P<0.05$, HF-S100A1 vs. HF-control) and PLB (sham-OP, $4.1 \pm 0.5$; HF-control, $2.3 \pm 0.7$; FCs-AdS100A1, $3.6 \pm 0.2 ; n=4 ; P<0.05$, HF$\mathrm{S} 100 \mathrm{~A} 1 \mathrm{vs}$. HF-control) protein amount compared with HF-control (Figure 12B). Protein data are given as relative AU normalized to CSQ that did not change among the groups (data not shown).

\section{Discussion}

S100A1 has recently been identified by our group as a novel positive regulator of cardiac contractility, as its cardiac-restricted overexpression improves cardiac contractile performance in vitro and in vivo in a cAMP-independent manner $(7,8)$. Since S100A1 protein has been shown to be downregulated in human and animal HF models $(5,6)$, we undertook this study to address whether S100A1 gene addition might reverse ventricular contractile dysfunction in failing myocardium. Using a postinfarct HF model in the rat, we provide evidence, for the first time to our knowledge, that adenovirus-mediated myocardial S100A1 gene delivery can restore S100A1 protein expression in failing myocardium and rescue contractile dysfunction both in vitro and in vivo. Restored S100A1 protein levels normalized dysfunctional intracellular $\mathrm{Ca}^{2+}$ and $\mathrm{Na}^{+}$handling, reversed fetal gene expression associated with $\mathrm{HF}$, and restored energy supply in failing myocardium. These results strongly support the hypothesis that altered expression of S100A1 in HF significantly contributes to $\mathrm{Ca}^{2+}$ signaling abnormalities and cardiac dysfunction and S100A1 is a key factor in the regulation of cardiac excitation-contraction coupling.

Adenovirus-mediated S100A1 gene transfer in vitro increased contractile performance of isolated FCs to levels observed in ventricular NFCs. Moreover, S100A1 gene addition almost totally normalized $\beta$-adrenergic contractile response in FCs, which was significantly attenuated under control conditions. This response was independent of any S100A1-mediated change in post- $\beta$ adrenergic receptor signaling. For example, S100A1 overexpression did not alter serine-16 phosphorylation of PLB after isoproterenol addition. This lack of altered $\beta$-adrenergic signaling in failing myocardium after S100A1 gene addition is similar to previous findings in transgenic mouse hearts overexpressing S100A1 protein (8). Thus, normalized S100A1 protein levels in FCs appear to have cAMP-independent and additive positive inotropic effects with $\beta$-adrenergic stimulation. This is also supported by previous findings in S100A1-deficient mouse hearts, which had impaired contractility despite normal $\beta$-adrenergic signaling (12).

Depressed contractility in HF is inherently linked to abnormal intracellular $\mathrm{Ca}^{2+}$ homeostasis. To gain further insight into the mechanisms by which S100A1 restores contractility in failing myocardium, we explored the impact of S100A1 gene addition on dys- 


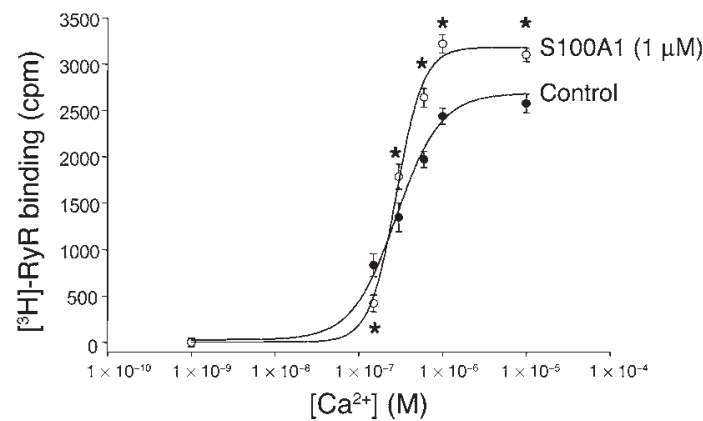

Figure 8

S100A1 modulates RyR2 activity in biphasic manner. Control SR vesicles show a $\mathrm{Ca}^{2+}$-dependent increase of $\left[{ }^{3} \mathrm{H}\right]-\mathrm{RyR}$ binding in the presence of $0.5 \mathrm{mM} \mathrm{Mg}^{2+}$ and $10 \mathrm{mM}$ caffeine. Addition of $1 \mu \mathrm{M} \mathrm{S} 100 \mathrm{~A} 1$ protein decreased $\left[{ }^{3} \mathrm{H}\right]-\mathrm{RyR}$ at $150 \mathrm{nM}$ free $\mathrm{Ca}^{2+}$ concentrations, while greater than approximately $300 \mathrm{nM}$ free $\mathrm{Ca}^{2+} \mathrm{S} 100 \mathrm{~A} 1$ increased $\left[{ }^{3} \mathrm{H}\right]$-RyR binding to the cardiac SR $\mathrm{Ca}^{2+}$-release channel. Data are presented as mean \pm SEM and expressed as cpm. Experiments $(n=3)$ were carried out in triplicate. ${ }^{\star} P<0.05$ vs. control.

functional $\mathrm{Ca}^{2+}$ cycling in FCs. S100A1 gene delivery was found to normalize $\mathrm{Ca}^{2+}$ transients and decrease diastolic $\mathrm{Ca}^{2+}$ overload in FCs. Overall, it seems that normalized S100A1 expression in FCs enhances contractility by restoring cytosolic $\mathrm{Ca}^{2+}$ handling, which has been suggested by previous studies in normal myocardium (7-9). Since impaired SR $\mathrm{Ca}^{2+}$ load is a major hallmark of HF (16) and contributes to depressed cytosolic $\mathrm{Ca}^{2+}$ cycling (2), we were interested in whether S100A1 restoration after gene delivery improved this aspect of SR $\mathrm{Ca}^{2+}$ signaling in FCs. Importantly, $\mathrm{S} 100 \mathrm{~A} 1$ restores $\mathrm{SR} \mathrm{Ca}^{2+}$ load in FCs, which may account, at least in part, for reconstituted $\mathrm{Ca}^{2+}$ transients and improved cardiac contractile performance in AdS100A1-treated FCs.

Using confocal laser microscopy, we found a colocalization in the SR between S100A1 and SERCA2 after AdS100A1 treatment and also found $\mathrm{a} \mathrm{Ca}^{2+}$-dependent association between these 2 proteins in FCs. Accordingly, we assessed the influence of normalized S100A1 levels on SERCA2 activity in failing myocardium, since the above results with increased SR $\mathrm{Ca}^{2+}$ load may be due to increased $\mathrm{Ca}^{2+}$ uptake. Importantly, S100A1 was found to enhance SERCA2 activity, which indicates that restored SR $\mathrm{Ca}^{2+}$ content seen in AdS100A1treated FCs might be the result of this mechanistic enhancement of SR $\mathrm{Ca}^{2+}$ uptake. This was further supported by the finding that inhibition of SERCA2 abrogated this functional gain in S100A1overexpressing FCs. Moreover, testing of distinct S100A1 oligopeptides revealed that the carboxyl terminus of S100A1 is responsible for its enhancement of SERCA2 activity. Interestingly, this result is consistent with previous studies showing that this domain of S100A1 is involved in modulating the activity of target proteins such as RyR1 in skeletal muscle (11). S100A1 was also found both to enhance $\mathrm{Ca}^{2+}$-dependent SERCA2 activity and to interact with the $\mathrm{SR} \mathrm{Ca}^{2+}$ pump in the context of a noncardiac cellular environment. Therefore, normalized S100A1 protein expression in HF appears to enhance $\mathrm{SR} \mathrm{Ca}^{2+}$ load in failing myocardium by increasing SERCA2 activity through a $\mathrm{Ca}^{2+}$-dependent interaction with the carboxyl domain of this S100 family member. Further studies are needed to determine the specific mechanism responsible for the enhancement of SERCA2 activity by this domain of S100A1 in myocardial SR.

$\mathrm{SR} \mathrm{Ca}{ }^{2+}$ load is balanced both by diastolic $\mathrm{Ca}^{2+}$ uptake and $\mathrm{Ca}^{2+}$ leakage, and enhanced diastolic $\mathrm{Ca}^{2+}$ leakage in failing myocardium can contribute to impaired SR $\mathrm{Ca}^{2+}$ content $(2,16)$. Interestingly, normalized S100A1 protein levels after AdS100A1 treatment lead to a decrease in the SR Ca ${ }^{2+}$ leakage in FCs. This could be due to an effect of S100A1 on RyR2, as we found a colocalization between these 2 SR proteins as well as a $\mathrm{Ca}^{2+}$-dependent association. This notion is further supported by the finding that S100A1 apparently reduces RyR2 activity at diastolic $\mathrm{Ca}^{2+}$ concentrations, as indicated by reduced $\left[{ }^{3} \mathrm{H}\right]$-ryanodine binding. Overall, these results suggest that restored $\mathrm{SR} \mathrm{Ca}^{2+}$ load in response to S100A1 gene addition is caused both by enhanced $\mathrm{Ca}^{2+}$ uptake and decreased $\mathrm{Ca}^{2+}$ leakage. This is significant, as it could mean that this mechanism is responsible for the decreased diastolic $\left[\mathrm{Ca}^{2+}\right]_{\mathrm{i}}$ in AdS100A1-treated FCs. However, our results suggest that S100A1 apparently influences RyR2 activity in a biphasic manner. Increasing free $\mathrm{Ca}^{2+}$ concentrations above $300 \mathrm{nM}$ resulted in enhanced $\left[{ }^{3} \mathrm{H}\right]$-ryanodine binding suggesting that S100A1 enhances RyR2 activity at supradiastolic $\mathrm{Ca}^{2+}$ concentrations. Given the fact that S100A1 has previously shown to enhance $\mathrm{Ca}^{2+}$ induced $\mathrm{SR} \mathrm{Ca}{ }^{2+}$ release in nonfailing myocardium (8), enhanced RyR2 activity might also contribute to normalized excitation-contraction coupling in FCs after S100A1 gene addition. Further studies are required to detail the mechanism underlying the biphasic effect of S100A1 on diastolic and systolic SR $\mathrm{Ca}^{2+}$ release channel function in failing and normal myocardium.

Since abnormal intracellular $\mathrm{Na}^{+}$handling has also been associated with HF (17), we addressed the impact of S100A1 gene transfer on $\left[\mathrm{Na}^{+}\right]_{\mathrm{i}}$ overload in FCs in vitro. Importantly, this defect, which can cause proarrythmogenic actions and ventricular remodeling (17), was also normalized by S100A1 gene transfer. Since suppressed SR function in HF can favor diastolic $\mathrm{Ca}^{2+}$ efflux via the NCX forward mode (17), this SR dysfunction might essentially contribute to increased $\left[\mathrm{Na}^{+}\right]_{\mathrm{i}}$ in failing myocardium. Considering the fact that
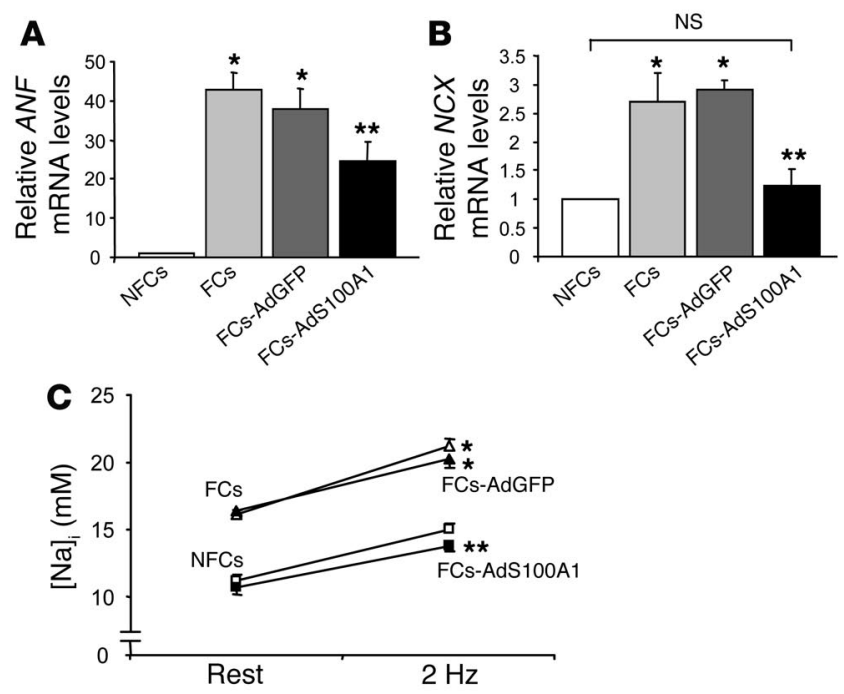

\section{Figure 9}

Effect of adenovirally expressed S100A1 on fetal gene expression and $\mathrm{Na}^{+}$-handling in FCs. (A) Average relative mRNA expression for ANF (upper panel) and (B) NCX (lower panel). 18S rRNA signals were used for normalization. $n=6$. (C) Normalization of $\left[\mathrm{Na}^{+}\right]_{i}$ in FCs following S100A1 gene transfer $(n=40$ cells from 4 different preparations; FCs [open triangles], FCs-AdGFP [filled triangles], NFCs [open squares], FCs-AdS100A1 [filled squares]). ${ }^{*} P<0.01$ compared with NFCs; ${ }^{* *} P<0.01$ compared with FCs and FCs-AdGFP; $P=$ NS, NFCs vs. FCs-AdS100A1. Data are presented as mean \pm SEM. 

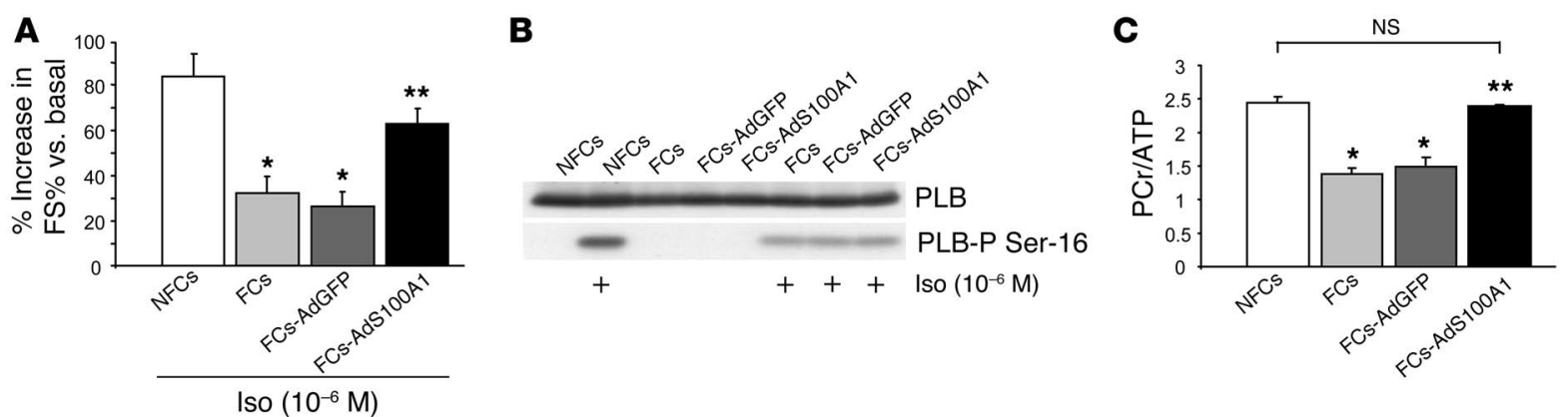

\section{Figure 10}

Adenoviral S100A1 gene delivery improves contractile reserve and normalizes energy supply in FCs. (A) Improved $\beta$-adrenergic stimulated contractility due to S100A1 gene addition in FCs ( $n=30$ cells from 3 different preparations). (B) Representative Western blots for total PLB (upper panel) and phosphorylated PLB (PLB-P Ser-16, lower panel) levels in NFCs, FCs, FCs-AdGFP, and FCs-AdS100A1-infected FCs under basal conditions and in response to isoproterenol (Iso, $10^{-6} \mathrm{M}$ ). (C) Normalization of PCr/ATP ratio in FCs following S100A1 gene addition. Average results for PCr/ATP ratio of each experimental group. $n=4$; ${ }^{*} P<0.01$ compared with NFCs; ${ }^{\star \star} P<0.01$ compared with FCs and FCs-AdGFP; $P=\mathrm{NS}, \mathrm{NFC}$ v vs. FCs-AdS100A1. Data are presented as mean \pm SEM.

SR Ca ${ }^{2+}$ load was normalized after S100A1 gene transfer, it is possible that S100A1-mediated enhancement of $\mathrm{Ca}^{2+}$ uptake enables the SR to better compete with NCX for diastolic $\left[\mathrm{Ca}^{2+}\right]_{\mathrm{i}}$ elimination. In turn, this effect might therefore reduce sarcolemmal $\left[\mathrm{Na}^{+}\right]_{\mathrm{i}}$ influx and contribute to reduction in $\left[\mathrm{Na}^{+}\right]_{\mathrm{i}}$. However, with regard to the complex network of ion channels and transporters regulating both cardiac $\mathrm{Ca}^{2+}$ and $\mathrm{Na}^{+}$homeostasis (17), elucidating the exact mechanisms underlying the beneficial effects of S100A1 on $\mathrm{Ca}^{2+}$ and $\mathrm{Na}^{+}$ handling in FCs warrants further investigation.

Decreased energy reserve via the creatine kinase reaction is also a characteristic finding both in human and experimental HF (18). Normalization of S100A1 protein in FCs restored the depressed $\mathrm{Pcr} /$ ATP ratio to normal values. Since SERCA2 activity is the reaction most vulnerable to a decrease in free energy released from ATP hydrolysis (19), normalized energy transfer might also account for improved $\mathrm{SR} \mathrm{Ca}^{2+}$ uptake in our experimental setting, despite sustained suppression of the $\mathrm{Ca}^{2+}$ pump. Thus, S100A1 gene addition also appears to normalize impaired energy supply in FCs. With regard to diastolic $\left[\mathrm{Ca}^{2+}\right]_{i}$ overload that essentially contributes to impaired mitochondrial function in failing myocardium, the S100A1-mediated decrease of diastolic $\left[\mathrm{Ca}^{2+}\right]_{\mathrm{i}}$ might in part contribute to the correction of the decreased Pcr/ATP ratio. Since S100A1 has previously been shown to also reside in the outer membrane of mitochondria within cardiomyocytes (20), this finding strongly supports the notion that this $\mathrm{Ca}^{2+}$-binding protein might also support mitochondrial function, which is the subject of current investigations. Moreover, we speculate that the increase of free energy released from ATP hydrolysis might also restore, at least in part, depressed $\mathrm{Na}^{+} / \mathrm{K}^{+}$-ATPase activity in FCs (17), which might also contribute to the S100A1-mediated normalized $\left[\mathrm{Na}^{+}\right]_{\mathrm{i}}$ discussed above.

Our in vitro results indicate that S100A1 normalization via gene transfer to the heart may represent a novel therapeutic strategy for HF. However, the ultimate question is whether similar results may occur in vivo after myocardial gene delivery of S100A1. To test this, we delivered AdS100A1 via the coronary arteries to postinfarcted rat hearts that were in overt HF. Importantly, 7 days after intracoronary S100A1 gene delivery, S100A1 protein was normalized in failing myocardium, and this resulted in markedly improved contractile function of failing hearts in vivo. Although gene delivery to the rat heart was shown to be global in nature, it was not entirely homogenous, and regional overexpression may account for the overall nor- malization of S100 in failing rat hearts. Importantly, however, this normalization of myocardial S100A1 essentially restored to almost normal both the peak rate of LV pressure rise and LVESP, reflecting a rescue of in vivo cardiac systolic function. This is significant due to the continued presence of a large LV infarct. Similarly, S100A1 gene transfer subsequently decreased elevated LVEDP to levels seen in nonfailing hearts, which demonstrates improved diastolic function as well. In contrast, delivery of the control AdGFP (or saline) did not alter the diminished cardiac levels of S100A1, nor was there any improvement in cardiac function in vivo of the failing rat hearts. This in vivo rescue of myocardial function due to S100A1 restoration was also preserved after $\beta$-adrenergic stimulation, and importantly, S100A1 gene treatment did not alter heart rate.

In addition to studying in vivo hemodynamics, we also isolated ventricular myocytes from Ad100A1- or AdGFP-treated failing hearts. Importantly, we found that AdS100A1-positive cells had enhanced cellular contractility and intracellular $\mathrm{Ca}^{2+}$ cycling both under basal conditions and in response to $\beta$-adrenergic stimulation (data not shown), which supports the hypothesis that S100A1-mediated HF rescue in vivo is due to an increase in myocyte contractile function. Overall, this in vivo rescue appears to be due to similar mechanisms of restored SR function, as found in our in vitro study (discussed above).

As in the FCs in vitro, in vivo HF rescue via S100A1 gene delivery was associated with a reversal of upregulated fetal gene expression. Further, there was an apparent normalization of aberrant SERCA2/PLB ratios and NCX protein expression. These results are consistent with previous findings in NFCs in vitro, where S100A1 addition prevented fetal gene expression in response to $\alpha_{1}$-adrenergic stimulation (6). Thus, the downregulation of the S100A1 protein in HF might be permissive for the induction of genes that underlie myocardial hypertrophy and failure, whereas restoration of S100A1 protein both participates in thwarting expression of fetal genes and may maintain the genetic program that defines normal cardiac function. However, attenuated fetal gene expression may also be simply a secondary result of the normalization of $\mathrm{Ca}^{2+}$ cycling and end-diastolic pressure by S100A1 gene transfer.

Overall, we have shown for the first time to our knowledge that restoring S100A1 protein expression can rescue defective contractile performance of failing myocardium in vitro and in vivo due to 

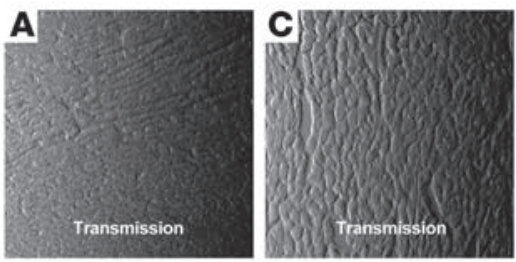

Sham-OP

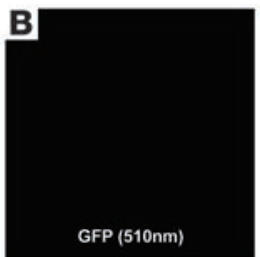

AdS100A1

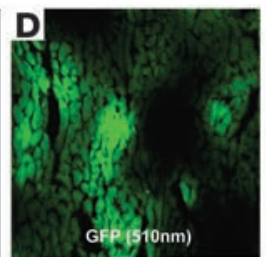

H

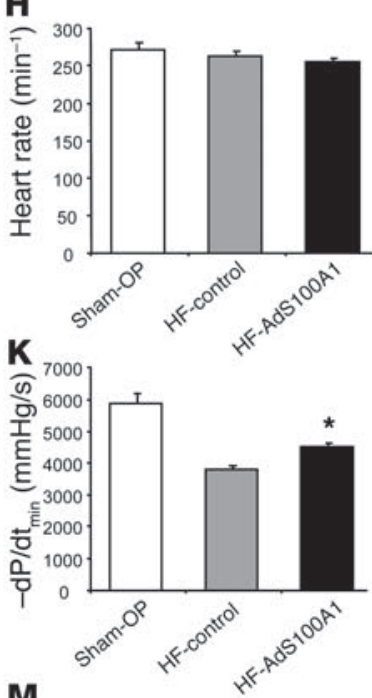

M

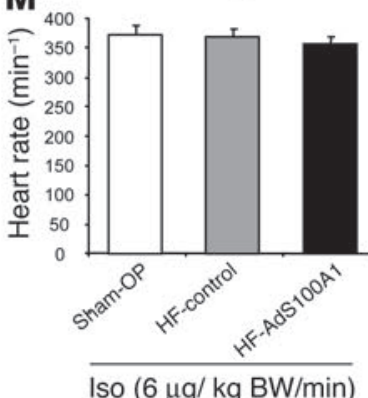

I
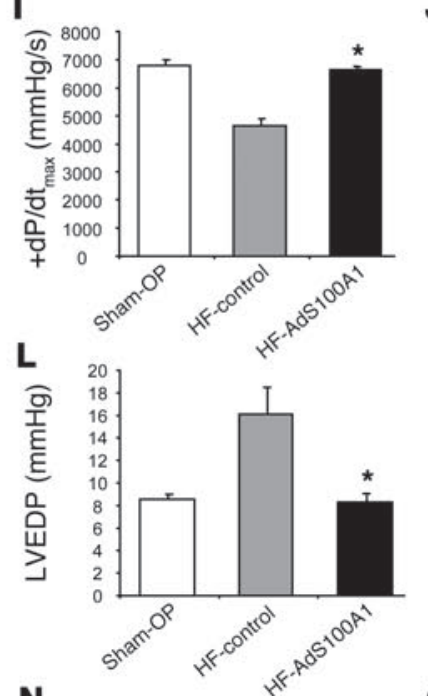

N
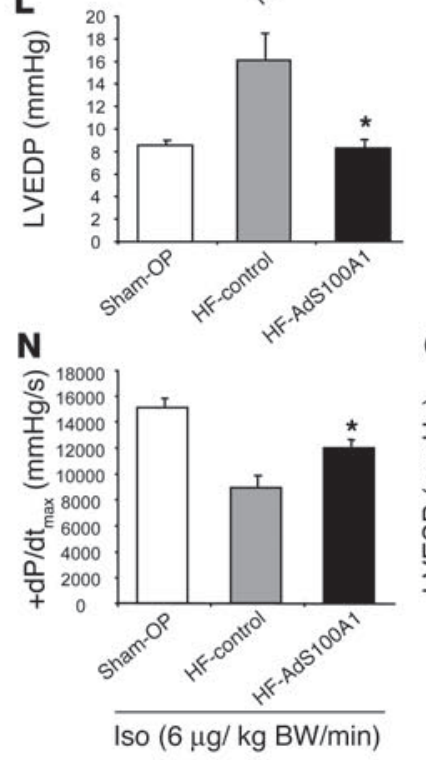

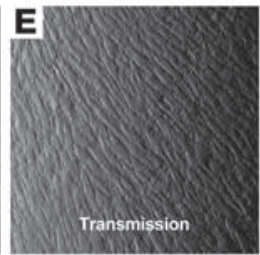

G

AdGFP

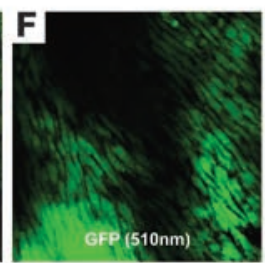

J

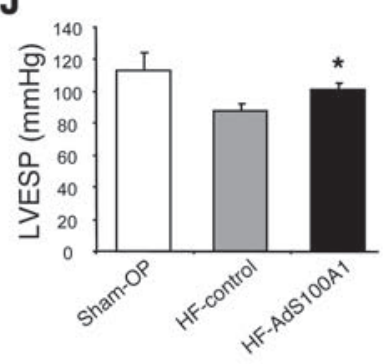

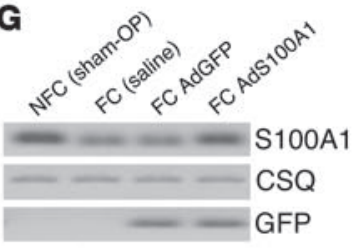

0

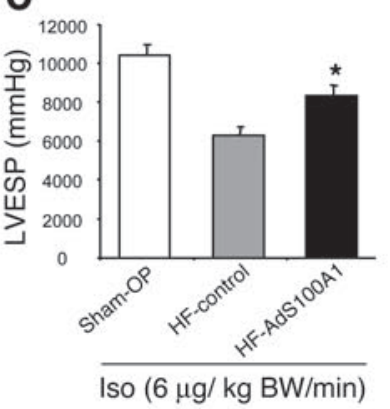

\section{Figure 11}

Intracoronary adenoviral S100A1 gene delivery rescues contractile dysfunction in vivo. (A-F) Representative corresponding Nomarski and GFPfluorescence images from midventricular cryosections of nonfailing (A and $\mathbf{B}$ ) and AdS100A1- (C and D) and AdGFP-treated (E and $\mathbf{F}$ ) failing myocardium. Magnification, $\times 10$. (G) Cardiac $\$ 100 A 1$ gene transfer reconstitutes S100A1 protein levels in failing myocardium in vivo. Representative Western blot of S100A1, CSQ and GFP expression in sham-OP nonfailing, saline-treated failing, and adenovirustreated (AdGFP/AdS100A1) failing myocardium. (H-L) Restoration of basal cardiac contractile performance after AdS100A1 gene transfer in vivo. (M-O) Preserved gain-in-function of AdS100A1-treated failing hearts in vivo after isoproterenol stimulation. Saline- and AdGFP-treated failing hearts displayed no significant difference in functional parameters and were combined to heart failure control group (HF-control; $n=14$ ). Data were obtained in isoflurane-anesthetized animals 7 days after intracoronary gene transfer or saline injection. Sham-OP; $n=7$, HF-AdS100A $1 ; n=7$. ${ }^{*} P<0.05$ HF-AdS100A1 vs. HF control. BW, body weight. improved cytosolic and SR $\mathrm{Ca}^{2+}$ cycling. The mechanism apparently involves enhancement of SERCA2 activity and modulation of RyR2 function. Importantly, the therapeutic effects of S100A1 normalization were not limited to improved $\mathrm{Ca}^{2+}$ cycling and contractile function, since normalized protein levels also restored impaired $\mathrm{Na}^{+}$homeostasis, cardiac energetics, and attenuation of fetal gene expression occurring in HF. Since S100A1 protein is downregulated in end-stage human HF, the present study clearly identifies this $\mathrm{Ca}^{2+}$ sensor as a key regulator of cardiac function, and its normalization appears to be a novel therapeutic target. Moreover, the targeting of S100A1 and SR $\mathrm{Ca}^{2+}$ cycling differs in many ways from conventional positive inotropic agents that increase chronotropy and energy consumption of failing myo- cardium, counterbalancing the positive effects on contractile strength. Our study does have its limitations, including the use of a first-generation adenoviral vector that limits our study duration. It will be important to examine the chronic effects of HF rescue by S100A1 gene delivery, and studies with improved vectors (i.e., adeno-associated vectors) may translate these findings into future S100A1 HF gene therapy clinical trials.

\section{Methods}

Generation of S100A1 adenovirus. To construct the S100A1 adenovirus (AdS100A1) containing both the human S100A1 and GFP cDNA, we used the method described by He et al. (21). An adenovirus containing GFP only (AdGFP) served as a control. The titers of stocks used for these studies mea- 
A

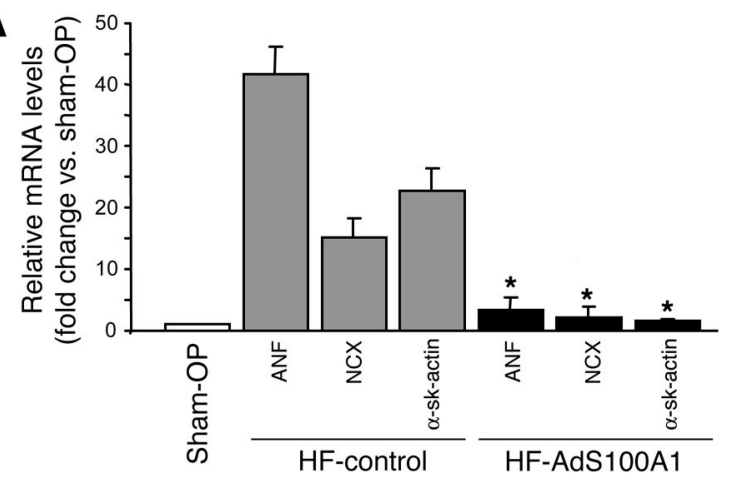

B

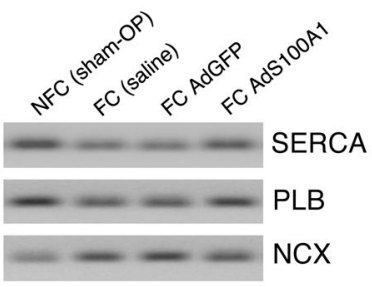

Figure 12

Intracoronary adenoviral S100A1 gene delivery reverses fetal gene expression and aberrant protein expression in failing myocardium in vivo. (A) Reversed fetal gene expression after S100A1 gene delivery in failing myocardium in vivo ( ${ }^{*} P<0.05 \mathrm{HF}-$ AdS100A1 vs. HF-control; $n=4$; samples were obtained from 3 different animals in each group). (B) Impact of S100A1 gene addition on SERCA2, PLB, and NCX protein amount in failing myocardium in vivo compared with saline-treated and AdGFP-treated failing myocardium ( $n=4$; samples were obtained from 3 different animals in each group). Data are presented as mean \pm SEM.

sured by plaque assays were $2 \times 10^{11} \mathrm{PFU} / \mathrm{ml}$ for AdS100A1 and $3 \times 10^{11}$ $\mathrm{PFU} / \mathrm{ml}$ for AdGFP. Aliquots were stored at $-80^{\circ} \mathrm{C}$.

Experimental rat $H F$ model. All animal procedures and experiments were performed in accordance with the guidelines of the IACUC of Thomas Jefferson University. Ten- to 12-week-old Sprague-Dawley rats of either sex $(n=30)$ were sedated i.p. with pentobarbital $(65 \mathrm{mg} / \mathrm{kg})$, intubated, and further anesthetized with isoflurane ( $2 \% \mathrm{vol} / \mathrm{vol})$ during mechanical ventilation. Hearts were exposed by median sternotomy and fixed by an apical suture, and a liquid nitrogen-cooled cryoprobe with a diameter of $7 \mathrm{~mm}$ was applied for 3 freeze-thaw cycles on the free LV anterior wall. The chest was then closed, and animals were transferred back to their cages, where they received appropriate analgesia. Four animals in the cryoinfarction group died during surgery. Sham-OP control animals $(n=9)$ underwent a similar procedure except that cryoprobes were not applied. Hearts of 6 cryoinfarcted animals were sectioned transaxially, and size of the infarcted $\mathrm{LV}$ area as a percent of total LV area was estimated to $32 \% \pm 3 \%$ by triphenyltetrazolium chloride (TTC) staining (Figure 1A) (22). There were no differences in infarct size between any subsequent groups (data not shown).

Cardiac catheterization and in vivo intracoronary myocardial adenovirus delivery. Twelve weeks after surgery, closed-chest cardiac catheterization was performed both in anesthetized (xylazine, $5 \mathrm{mg} / \mathrm{kg}$ body wt; ketamine, $100 \mathrm{mg} / \mathrm{kg}$ body wt) sham-OP and cryoinfarcted animals, as previously described (8). A 2.5F catheter (Millar Instruments) was inserted into the left main carotid artery and advanced into the LV. In vivo basal and isoproterenol-stimulated hemodynamic analysis (Bemon32/Amon32 software, version 3.2; Ingenieurbuero Jaeckel) included heart rate (bpm), maximal $\left(\mathrm{LVdP} / \mathrm{dt}_{\max }\right)$ and minimal $\left(\mathrm{LVdP} / \mathrm{dt}_{\min }\right)$ first derivative of $\mathrm{LV}$ pressure, LVEDP, and maximal LVESP. Isoproterenol $(6 \mu \mathrm{g} / \mathrm{kg} / \mathrm{min})$ was administered via the jugular vein, and data were acquired when functional parameters reached a stable plateau. Afterwards, in vivo cardiac gene delivery was performed as previously described by the Hajjar group (15, 23). Animals were divided in 3 groups receiving either $200 \mu \mathrm{l} \mathrm{AdS100A1}$ $\left(1 \times 10^{10} \mathrm{PFU} ; n=8\right)$ or AdGFP $\left(1 \times 10^{10} \mathrm{PFU} ; n=8\right)$ in solution via a $22 \mathrm{G}$ catheter $(\mathrm{BD})$ advanced from the apex of the LV to the aortic root. The third failing group $(n=8)$ received saline injection only. The aorta and the main pulmonary artery were clamped distal to the site of the catheter and the solution injected. The clamp was maintained for 10 seconds, during which the heart pumped against a closed isovolumic system, allowing the adenovirus to circulate down the coronary arteries and perfuse the heart. In each group, 1 animal died during this procedure. After removal of air and blood, the chest was closed, and animals were extubated and transferred back to their cages. Seven days after gene transfer, in vivo cardiac function was reevaluated as described above via the right main carotid artery. After cardiac catheterization, same animals were used for isolation of ventricular cardiomyocytes. Transfection efficiency was monitored by GFP fluorescence $(510 \mathrm{~nm})$ in cryosectioned hearts $(20 \mu \mathrm{m}$ sections; magnification, $\times 10$ ). To confirm specificity of the GFP emission, the same offset for suppressed background of nontransfected hearts excited at $488 \mathrm{~nm}$ was applied to adenovirus-transfected hearts (Figure 5, A-F), and additional measurements were taken below and above the GFP excitation spectrum (data not shown).

Cardiomyocyte isolation and in vitro gene transfer. Adult LV cardiomyocytes were obtained using a collagenase digestion method as described in detail elsewhere (9). Adenoviral transfection (5 PFU/cell) of isolated ventricular cardiomyocytes from saline-treated failing hearts $(n=4)$ was carried out in HEPES-modified medium 199 (M199), and cells were maintained in M199 for 24 hours at $37^{\circ} \mathrm{C}, 95 \% \mathrm{O}_{2} / 5 \% \mathrm{CO}_{2}$. Cardiomyocytes that were used to measure contractility and $\mathrm{Ca}^{2+}$ and $\mathrm{Na}^{+}$levels were plated with a density of $30,000 \mathrm{cells} / \mathrm{cm}^{2}$ on laminin-coated glass dishes. For analysis of mRNA and protein expression and energetic metabolites, cardiomyocytes were plated with a density of 150,000 and 300,000 cells $/ \mathrm{cm}^{2}$, respectively.

Indirect immunofluorescence. Imaging of adenovirus-treated ventricular cardiomyocytes was carried out as described previously with minor modifications (13). Briefly, adenoviral transfection (5 PFU/cell) of isolated cells was carried out on coated glass coverslips. After 24 hours, cells were fixed, permeabilized, and labeled with anti-S100A1 (SA 5632; Eurogentec; 1:300), anti-SERCA2 (Alexis Corp.; 1:500) or anti-RyR2 (Alexis Corp.; 1:500) antibodies, followed by the corresponding Cy3-conjugated (Jackson ImmunoResearch Laboratories Inc.; 1:3,000) and Cy5-conjugated (Jackson ImmunoResearch Laboratories Inc.; 1:400) secondary antibodies. Confocal images were obtained using a $\times 40$ objective on a Leica Microsystems TCS SP laser scanning confocal microscope. Digitized confocal images were processed by Leica confocal software (LCS, version 2.5) and Adobe Photoshop (version 6.0).

Cardiomyocyte contractility. Contractile properties of isolated ventricular cardiomyocytes were obtained by video-edge-detection, as described previously (7). Analysis of in vivo- and in vitro-transfected cardiomyocytes was carried out immediately after isolation and 24 hours after adenoviral gene transfer, respectively. Analysis of steady-state twitches at 2-Hz field stimulation, $37^{\circ} \mathrm{C}$, and $2 \mathrm{mM}\left[\mathrm{Ca}^{2+}\right]_{\mathrm{e}}$ was performed by custom-designed software written in LabView (version 5.0; National Instruments).

Intracellular $\mathrm{Ca}^{2+}$ transients and $\mathrm{SR} \mathrm{Ca}^{2+}$ load. Calibration and assessment of intracellular $\mathrm{Ca}^{2+}$ transients and SR $\mathrm{Ca}^{2+}$ load in field-stimulated ventricular cardiomyocytes was performed as described in detail elsewhere (8). Assessment of $\mathrm{Ca}^{2+}$ handling properties in isolated, fura-2/AM-loaded in vivo- and in vitro-transfected cardiomyocytes was carried out immediately after isolation and 24 hours after adenoviral gene delivery, respectively. Steady-state transients at $2-\mathrm{Hz}$ field stimulation, $37^{\circ} \mathrm{C}$, and $2 \mathrm{mM}\left[\mathrm{Ca}^{2+}\right]_{e}$ were analyzed by T.I.L.L Vision software (version 4.01). To avoid interfer- 
ence with fura-2 and GFP emission, we assessed fura-2 emission in both nontransfected and GFP-transfected cells, and increased GFP emission (5\%) was subtracted prior to calibration.

COS-1 cell culture and adenoviral transfection. COS-1 cells were maintained in DMEM supplemented with $10 \%$ FCS, penicillin/streptomycin (100 units $/ \mathrm{ml})$, and glutamine $(2 \mathrm{mM})$ at $37^{\circ} \mathrm{C}$ in an air-humidified atmosphere and grown to $80 \%$ confluency. Infections of cultured cells with recombinant adenovirus were performed with a multiplicity of 100 viral particles per cell in serum-free medium for 6 hours. Cells were either coinfected with S100A1 and SERCA2 adenovirus (graciously supplied by Roger Hajjar, Massachusetts General Hospital, Boston, Massachusetts, USA) or each virus alone. Cells were further grown in supplemented DMEM for 48 hours and harvested for preparation of microsomal fractions and Western blot analysis in ice-cold PBS ( $\mathrm{pH}$ 7.4) supplemented with Mini Complete EDTAfree protease inhibitors (1 tablet $/ 5 \mathrm{ml}$; Roche Applied Science).

$\mathrm{Ca}^{2+}$-ATPase measurements. Cardiac SR vesicles and microsomal fractions from in vitro adenovirus-treated FCs and COS cells, respectively, were prepared by density-gradient centrifugation as previously described $(n=3$ different preparations) $(8,24)$. COS microsomal fractions were prepared in the presence of $\mathrm{CaCl}_{2}(1 \mathrm{mM})$ to prevent depletion of overexpressed S100A1 protein. SERCA2 activity was assessed by the use of a pyruvate/ NADH-coupled enzymatic reaction (19).

$S R \mathrm{Ca}^{2+}$ leak assay. $\mathrm{Ca}^{2+}$ leak from $\mathrm{SR}$ vesicles derived from in vivo adenovirus-treated and control hearts ( $n=3$ in each group) was assessed by the use of the $\mathrm{Ca}^{2+}$ indicator Fluo-3, as described previously (25). S100A1 recombinant human protein and S100A1 peptides (N-terminal, N: AAs 2-16; hinge region, $\mathrm{H}$, AAs 42-54; C-terminal, C: AAs 75-94) were obtained as described elsewhere (11).

$\left[{ }^{3} \mathrm{H}\right]$-ryanodine binding. $\left[{ }^{3} \mathrm{H}\right]$-ryanodine binding experiments were performed from terminal SR vesicle preparations prepared from rat LV myocardium as previously described $(8,26)$. Briefly, membranes were incubated at $37^{\circ} \mathrm{C}$ with $6 \mathrm{nM}\left[{ }^{3} \mathrm{H}\right]$-ryanodine (PerkinElmer) in $300 \mu \mathrm{l}$ of $20 \mathrm{mM}$ PIPES, pH 7.1, $150 \mathrm{mM} \mathrm{KCl}, 0.5 \mathrm{mM} \mathrm{MgCl}_{2}, 15 \mathrm{mM} \mathrm{NaCl}$, EGTA $3 \mathrm{mM}, 10 \mathrm{mM}$ caffeine, $1 \%$ phosphatase inhibitors (Sigma-Aldrich; inhibitor mix I/II), Mini Complete EDTA free protease inhibitors ( 1 tablet $/ 5 \mathrm{ml}$; Roche Applied Science) and the indicated free $\mathrm{Ca}^{2+}$ concentrations either in the presence or absence of $1 \mu \mathrm{M}$ human recombinant S100A1 protein. Nonspecific binding was determined using 1,000-fold excess of unlabeled ryanodine. After 60 minutes, aliquots of the samples were diluted in $10 \mathrm{vol}-$ umes of ice-cold water and placed on Whatman GF/B filters preincubated with $2 \%$ polyethyleneimine in water. Filters were washed 3 times with $5 \mathrm{ml}$ of ice-cold 20 mM PIPES, pH 7.1, $150 \mathrm{mM} \mathrm{KCl}, 15 \mathrm{mM} \mathrm{NaCl}$. Radioactivity remaining on the filters was determined by liquid scintillation counting to obtain bound $\left[{ }^{3} \mathrm{H}\right]$-ryanodine.

Western blotting. Western blots to assess protein levels of S100A1 protein (S-2407; Sigma-Aldrich), SERCA2 (SA209-0100; Biomol), NCX (MA3926; Affinity BioReagents), CSQ (208915; Calbiochem), cardiac actin (Ac1-20.4.2; Progen Biotechnik GmbH), PLB (05-205; Upstate), Ser16PLB (07-052; Upstate), and GFP (837 1-1; BD Biosciences - Clontech) were done with samples of in vitro $(n=3)$ or in vivo $(n=7)$ adenovirustreated myocardium as well as transfected COS cells $(n=3)$, as described elsewhere (8). S100A1 protein $\left(M_{r}, 10,000\right)$ from cellular extracts was enriched by sequential size exclusion centrifugation columns (Microcon YM-50 and YM-3; Amicon).

Coimmunoprecipitations. Coimmunoprecipitation for S100A1 with SERCA2 and RyR2 was investigated in crude membrane preparations from in vitro adenovirus-treated FCs as described previously $(8,27)$. Interaction of S100A1 with SERCA2 was also tested in cell lysates from adenovirus-transfected COS cells. To exclude unspecific binding, we used anti-S100A1 (SA 5632) preincubated with the blocking peptide (hinge region, S100A1 AAs 42-54) as a control. Samples were processed by Western blot as described above, with minor modifications. Coimmunprecipitated samples for S100A1-SERCA2 and S100A1-RyR2 were stained with an anti-S100A1 (SA 5632; custom-made by Eurogentec), anti-SERCA2 (SA209-0100; Biomol), and anti-RyR2 (MA-3-925; ABR) antibody, followed by a corresponding pair of Alexa Fluor 680- (Molecular Probes) and IRDye 800CW- coupled (Rockland Inc.) secondary antibodies, respectively. Proteins were visualized with a LI-COR infrared imager (Odyssey), and pictures were processed by Odyssey version 1.2 infrared imaging software.

$R N A$ isolation, reverse transcription, and quantitative real-time PCR. Total RNA isolation, reverse transcription, and real-time RT-PCR were carried out for rat ANF (forward primer 5'-CCCGACCCAGCATGG-3', reverse primer 5'-CAACTGCTTTCTGAAAGGGGTG-3'; annealing temperature $60^{\circ} \mathrm{C}$ ), NCX (forward primer 5'-GCTCATATTACTGTAAGAAAGGGGTG-3', reverse primer 5'-GGCGGCGCTTCCCA-CAATGG-3'; annealing temperature $61^{\circ} \mathrm{C}$ ), $\alpha$-sk-actin (forward primer $5^{\prime}$-CAGCTCTGGCTCCCAGCACC$3^{\prime}$, reverse primer $5^{\prime}$-AATGGCTGGCTTTAATGCTTCA-3'; annealing temperature $\left.60^{\circ} \mathrm{C}\right)$ from in vitro- $(n=3)$ and in vivo-adenovirus-treated $(n=7)$ FCs by the use of an ABI Prism 7000 Sequence Detection System and the Platinum SYBR Green qPCR SuperMix-UDG (Invitrogen), as described elsewhere (10). 18s rRNA signals were used for normalization (forward primer 5'-TCAAGAACGAAAGTCGGAGG-3', reverse primer $5^{\prime}$-GGACATCTAAGGGCATCAC-3'; annealing temperature $60^{\circ} \mathrm{C}$ ). After amplification, a melting curve acquired by heating the product to $95^{\circ} \mathrm{C}$, cooling to and maintaining at $55^{\circ} \mathrm{C}$ for 20 seconds, then slowly $\left(0.5^{\circ} \mathrm{C} / \mathrm{s}\right)$ heating to $95^{\circ} \mathrm{C}$ was used to determine the specificity of PCR products, which were then confirmed by gel electrophoresis.

Measurement of intracellular $\mathrm{Na}^{+}$concentrations. Calibration and assessment of $\left[\mathrm{Na}^{+}\right]_{\mathrm{i}}$ of cardiomyocytes ( $n=3$ different preparations) was accomplished 24 hours after adenoviral delivery by the use of the $\mathrm{Na}^{+}$fluorescent dye SBFI-AM, as previously described (28). Analysis of $\left[\mathrm{Na}^{+}\right]_{i}$ was performed at rest and $2 \mathrm{~Hz}$ at $37^{\circ} \mathrm{C}$ and $2 \mathrm{mM}\left[\mathrm{Ca}^{2+}\right]_{\mathrm{e}}$ with T.I.L.L Vision software (version 4.01).

Assessment of high-energy phosphates. PCr and ATP levels were measured in cellular homogenates 24 hours after adenoviral treatment $(n=3$ different preparations), as described previously (29).

Statistics. Data are generally expressed as mean \pm SEM. An unpaired 2 -tailed Student's $t$ test and 2-way repeated measures ANOVA were performed for statistical comparisons. For all tests, a $P$ value of less than 0.05 was considered to be significant.

\section{Acknowledgments}

This work was supported in part by grants from the Deutsche Forschungsgemeinschaft (Mo 1066/1-1, to P. Most, and 1083/1-1, to A. Remppis), the Forschungsförderungsprogramm Medizinische Fakultät der Universität Heidelberg (93/2002, to P. Most), and the NIH (R01 HL56205 and R01 HL59533, to W.J. Koch). We also wish to thank Roger Hajjar for supplying the SERCA2 adenovirus.

Received for publication March 1, 2004, and accepted in revised form October 5, 2004.

Address correspondence to: Patrick Most or Walter. J. Koch, Center for Translational Medicine, Department of Medicine, Thomas Jefferson University, Philadelphia, Pennsylvania 19107, USA. Phone: (215) 955-9982; Fax: (215) 503-5728; E-mail: patrick.most@jefferson.edu orwalter.koch@jefferson.edu.

Patrick Most, Sven T. Pleger, and Mirko Völkers contributed equally to this work. 
1. American Heart Association. 2003. Heart disease and stroke statistics - 2004 update. American Heart Association. Dallas, Texas, USA. http://www.americanheart.org/presenter.jhtml?identifier $=1928$.

2. Marks, A.R. 2003. Calcium and the heart: a question of life and death. J. Clin. Invest. 111:597-600. doi:10.1172/JCI200318067.

3. Hasenfuss, G. 1998. Alterations of calcium-regulatory proteins in heart failure. Cardiovasc. Res. 37:279-289.

4. Donato, R. 2003. Intracellular and extracellular roles of S100 proteins. Microsc. Res. Tech. 60:540-551.

5. Remppis, A., et al. 1996. Altered expression of the $\mathrm{Ca}(2+)$-binding protein $\mathrm{S} 100 \mathrm{~A} 1$ in human cardiomyopathy. Biochim. Biophys. Acta. 1313:253-257.

6. Tsoporis, J.N., Marks, A., Zimmer, D.B., McMahon, C., and Parker, T.G. 2003. The myocardial protein S100A1 plays a role in the maintenance of normal gene expression in the adult heart. Mol. Cell. Biochem. 242:27-33.

7. Most, P., et al. 2001. S100A1: a regulator of myocardial contractility. Proc. Natl. Acad. Sci. U. S. A. 98:13889-13894.

8. Most, P., et al. 2003. Transgenic overexpression of the $\mathrm{Ca} 2+$ binding protein S100A1 in the heart leads to increased in vivo myocardial contractile performance. J. Biol. Chem. 278:33809-33817.

9. Remppis, A., et al. 2002. The small EF-hand $\mathrm{Ca}^{2+}$ binding protein S100A1 increases contractility and $\mathrm{Ca}^{2+}$ cycling in rat cardiac myocytes. Basic Res. Cardiol. 97:I/56-I/62.

10. Remppis, A., et al. 2004. S100A1 gene transfer: a strategy to strengthen engineered cardiac grafts. J. Gene Med. 6:387-394.
11. Most, P., et al. 2003. The C-terminus (aa 75-94) and the linker region (aa 42-54) of the $\mathrm{Ca} 2+$ binding protein S100A1 differentially enhance sarcoplasmic Ca2 + release in murine skinned skeletal muscle fibres. J. Biol. Chem. 278:26356-26364.

12. Du, X.J., et al. 2002. Impaired cardiac contractility response to hemodynamic stress in S100A1-deficient mice. Mol. Cell. Biol. 22:2821-2829.

13. Most, P., et al. 2003. Extracellular S100A1 protein inhibits apoptosis in ventricular cardiomyocytes via activation of the extracellular-regulated kinase (ERK1/2) pathway. J. Biol. Chem. 278:48404-48412.

14. Treves, S., et al. 1997. Interaction of S100A1 with the $\mathrm{Ca} 2+$ release channel (ryanodine receptor) of skeletal muscle. Biochemistry. 36:11496-11503.

15. Hajjar, R.J., et al. 1998. Modulation of ventricular function through gene transfer in vivo. Proc. Natl. Acad. Sci. U. S. A. 95:5251-5256.

16. Bers, D.M. 2002. Cardiac excitation-contraction coupling. Nature. 415:198-205.

17. Pieske, B., and Houser, S.R. 2003. $\left[\mathrm{Na}^{+}\right] \mathrm{i}$ handling in the failing heart. Cardiovasc. Res. 57:874-886.

18. Balaban, R.S. 2002. Cardiac energy metabolism homeostasis: role of cytosolic calcium. J. Mol. Cell. Cardiol 34:1259-1271.

19. del Monte, F., et al. 1999. Restoration of contractile function in isolated cardiomyocytes from failing human hearts by gene transfer of SERCA2a. Circulation. 1000:2308-2311.

20. Haimoto, H., and Kato, K. 1988. S100a0 (alpha alpha) protein in cardiac muscle. Isolation from human cardiac muscle and ultrastructural localization. Eur. J. Biochem. 171:409-415.

21. He, T.C., et al. 1998. A simplified system for gen- erating recombinant adenoviruses. Proc. Natl. Acad. Sci.U. S. A. 95:2509-2514.

22. Parsa, C.J., et al. 2003. A novel protective effect of erythropoietin in the infarcted heart. J. Clin. Invest. 112:999-1007. doi:10.1172/JCI200318200.

23. Miyamoto, M.I., et al. 2000. Adenoviral gene transfer of SERCA2a improves left-ventricular function in aortic-banded rats in transition to heart failure. Proc. Natl. Acad. Sci. U. S. A. 97:793-798.

24. Strock, C., et al. 1998. Direct demonstration of $\mathrm{Ca} 2+$ binding defects in sarco-endoplasmic reticulum Ca2 + ATPase mutants overexpressed in COS-1 cells transfected with adenovirus vectors. J. Biol. Chem. 273:15104-15109.

25. Yano, M., et al. 2000. Altered stoichiometry of FKBP12.6 versus ryanodine receptor as a cause of abnormal Ca2+ leak through ryanodine receptor in heart failure. Circulation. 102:2131-2136.

26. Yamaguchi, N., Xu, L., Pasek, D.A., Evans, K.E., and Meissner, G. 2003. Molecular basis of calmodulin binding to cardiac muscle Ca2+ release channel (ryanodine receptor). J. Biol. Chem. 278:23480-23486.

27. Kiewitz, R., et al. 2003. $\mathrm{Ca}(2+)$-dependent interaction of S100A1 with the sarcoplasmic reticulum $\mathrm{Ca}(2+)$-ATPase $2 \mathrm{a}$ and phospholamban in the human heart. Biochem. Biophys. Res. Commun. 306:550-557.

28. Despa, S., Islam, M.A., Pogwizd, S.M., and Bers, D.M. 2002. Intracellular $\left[\mathrm{Na}^{+}\right]$and $\mathrm{Na}+$ pump rate in rat and rabbit ventricular myocytes. J. Physiol. 539:133-143.

29. Arrio-Dupont, M., and de Nay, D. 1988. High-energy phosphates in quiescent, beating and contracted cardiac cells. Biochim. Biophys. Acta. 934:264-268. 